\title{
LA PARTICIPACIÓN POLÍTICA DE LAS ELITES LOCALES EN EL GOBIERNO DE LAS CIUDADES CASTELLANAS EN LA BAJA EDAD MEDIA BANDOS Y CONFLICTOS DE INTERESES \\ (PAREDES DE NAVA, FINAL DEL S.XIV-INICIO DEL S. XV) ${ }^{1}$
}

\author{
POLITICAL PARTICIPATION OF LOCAL ELITES \\ IN THE GOVERNMENT OF CASTILIAN TOWNS DURING THE LATE MIDDLE AGES. \\ FACTIONS AND CONFLICT OF INTERESTS \\ (PAREDES DE NAVA, END OF THE 14TH CENTURY-BEGINNING OF THE 15TH CENTURY)
}

\author{
VÍCTOR MuÑoz GóMEZ \\ Universidad de Valladolid
}

\begin{abstract}
Resumen: En este artículo proponemos una aproximación a las formas de participación política de las elites urbanas en el gobierno de las ciudades de la Corona de Castilla en la Baja Edad Media. El objeto de estudio elegido para ello lo aporta el análisis del conflicto entre bandos por el gobierno concejil desarrollado entre 1401 y 1403 en la villa castellana de Paredes de Nava, lugar de señorío del infante Fernando de Antequera. A partir del mismo, podemos observar la diversidad de factores que condicionaban la alineación de estas elites durante este tipo de pugnas, más allá de la existencia de estructuras más o menos formalizadas, para encauzar la concurrencia política.
\end{abstract}

Palabras clave: Villa; Conflicto; Señorío; Bando urbano; Pacificación Paredes de Nava; Infante Fernando de Antequera; Castilla. Siglos XIV y XV.

\begin{abstract}
This article approaches to the forms of political participation into the government of the Crown of Castile by the municipal elites during the Late Middle Ages. We have chosen as object of research for this purpose the struggle between urban factions for the counciliar government happened in Paredes de Nava, a seigniorial town upon the infante Fernando of Antequera, in 1401-1403. In base of this case, we can observe a great number of factors whom influenced the alignment of these elites throughout these conflicts, beyond the existence of more or less formalized structures able to channel urban political concurrence.
\end{abstract}

Keywords: Town; Conflict; Lordship; Urban faction; Pacification; Paredes de Nava; "Infante" Fernando of Antequera; Castile; 14th-15th centuries.

${ }^{1}$ Este trabajo ha sido realizado a partir del disfrute de una beca/contrato de postgrado del Programa Nacional de Formación de Profesorado Universitario del Ministerio de Educación y Ciencia, referencia AP-2004-5182.

El presente artículo es la plasmación escrita de algunas de las reflexiones vertidas en mi intervención en el coloquio internacional organizado por la Dra. María Teresa Ferrer i Mallol en la Institución Milá y Fontanals (CSIC) los días 4 y 5 de octubre de 2007, bajo el título de Conflictivitat $i$ vies de solució a la Mediterrània medieval. Aprovecho la ocasión para agradecer a la Dra. Roser Salicrú i Lluch la propuesta que me hizo para participar en esta reunión científica y, por supuesto, la invitación expresa de la Dra. Ferrer i Mallol para colaborar en la misma. Quiero hacer extensivo mi agradecimiento a todo el personal def Departamento de Estudios Medievales de la Institución Milá y Fontanals por su acogida y apoyo durante los meses que tuve el placer de compartir con ellos en Barcelona, con especial atención a la Dra. Salicrú, quien tuvo la amabilidad de guiar mis pasos allí. 


\section{SUMARIO}

1. Introducción.- 2. La villa de Paredes de Nava bajo el señorío de Fernando de Antequera.3. Bandos, conflicto y respuesta señorial. El conflicto de 1401-1403.- 4. En las raíces del conflicto: facciones, solidaridades y concurrencia de intereses.- 5. Conclusiones.- Apéndice documental.

\section{INTRODUCCIÓN}

La complejidad política del mundo urbano de la Corona de Castilla en la Baja Edad Media es un hecho que no ha escapado al interés de la historiografía en las últimas décadas ${ }^{2}$. Las investigaciones desarrolladas en estos años han permitido aproximarnos a un universo de estructuras concejiles ciertamente sofisticadas, dotadas de una fuerte personalidad política de comunidad sostenida sobre arraigadas tradiciones jurídicas e institucionales, en las que la competencia y el equilibrio por la preeminencia social y económica en el ámbito local enfrentaba a distintos actores, tanto elites municipales como bases sociales pecheras, por la concurrencia al concejo y el control político del mismo, a menudo de forma abierta y cruenta ${ }^{3}$.

Una de las más típicas manifestaciones de estas oposiciones en el seno de la sociedad urbana castellana fueron los enfrentamientos por el predominio político urbano y por el dominio de sus resortes institucionales entre los individuos que integraban el sector más prominente de aquella, a menudo organizados en diferentes formas de partidos o bandos ${ }^{4}$. El desarrollo de nuestras investigaciones sobre el estado señorial y el entorno clientelar del

${ }^{2}$ Prueba evidente de ello lo ofrecen recientes estados de la cuestión, siendo más que destacable el de María ASENJO GONZÁLEZ, Las ciudades medievales castellanas. Balance y perspectivas de su desarrollo historiográfico (1990-2004), "En la España medieval”, 28 (2005), pp. 415-453.

${ }^{3}$ Valgan para ilustrar las dinámicas propias del subsistema de poder urbano -resultado de la aplicación metodológica de la teoría general de sistemas al análisis de las instancias y relaciones de poder dentro de la esfera municipal castellana (José María MONSALVO ANTóN, El sistema politico concejil: el ejemplo del señorío medieval de Alba de Tormes y su concejo de villa y tierra, Salamanca, 1988, en concreto, pp. 133-141, 265-359)-, y de los distintos agentes integrados en él amén del debate existente al respecto de estos conceptos y elementos los siguientes trabajos: J.M Ma Monsalvo ANTÓN, Poder político y aparatos de estado en la Castilla bajomedieval. Consideraciones sobre su problemática, "Studia Historica. Historia Medieval", IV/2 (1986); IDEM, El sistema político concejil; IDEM, Vertebración jurídica de los concejos castellanos de la meseta durante la época del régimen medieval: la distribución social del poder, en Concejos y ciudades en la Edad Media hispanica: "II Congreso de Estudios Medievales. Fundación SánchezAlbornoz", León, 1990, pp. 357-428; IDEM, Historia de los poderes medievales, del Derecho a la Antropología (el ejemplo castellano: monarquía, concejos y señorios en los siglos XII-XV), en Carlos BARROS (ed.) "Historia a debate. Medieval", Santiago de Compostela 1995, pp. 81-149; María ASENJO GONŹÁLEZ, Sociedad y vida política en las ciudades de la Corona de Castilla: Reflexiones sobre un debate, "Medievalismo" 5 (1995), pp. 89-126; María Isabel del VAL VÁLDIVIESO Aspiraciones y actitudes socio-políticas. Una aproximación a la sociedad urbana de la Castilla bajomedieval, en Juan Antonio BONACHÍA HERNANDO (coord.) "La ciudad medieval. Aspectos de la vida urbana en la Castilla bajomedieval", Valladolid, 19396.

${ }^{4}$ Véase a modo de introducción el que fue un trabajo pionero en este sentido (Miguel Ángel LADERO OUESADA, Linajes, bandos y parcialidades en la vida politica de las ciudades castellanas (siglos XIV y XV), en Bandos y querellas dinásticas en España al final de la Edad Media "Actas del Coloquio celebrado en la Biḅlioteca de España de París en mayo de 1987", París, 1991, pp. 105-134), además de las obras citadas en la nota 3. Tendremos ocasión de volver sobre este tema con mayor profundidad más adelante. 
infante Fernando de Antequera y de Leonor de Alburquerque nos ha ofrecido la posibilidad de acercarnos a un, como veremos, muy particular ejemplo de este tipo de conflictos, documentado en la villa de Paredes de Nava entre 1401 y 1403, a la sazón lugar de señorío de estos miembros de la familia real castellana. La modesta dimensión urbana de esta villa y su condición señorial nos sitúan ante un objeto de estudio atípico por su contexto respecto a los ofrecidos por las luchas entre facciones oligárquicas de las grandes ciudades realengas de la Corona de Castilla ${ }^{5}$. La disección que proponemos del enfrentamiento entre los partidos en que se encuadraba la elite local de este pequeño centro urbano, además de darnos a conocer el objeto concreto de esta pugna, sus protagonistas enfrentados y los objetivos que perseguían las partes en conflicto, pretende ir más allá de lo que pudiera considerarse una aportación de carácter local a sumar a la amplia casuística de luchas banderizas en el mundo urbano castellano. Así, la aproximación en nuestro ejemplo paredeño a una forma de organización de estas parcialidades escasamente formalizadas, tal y como podremos apreciar, da pie para la reflexión sobre un tema mucho más sugerente como el de la concurrencia política de las elites municipales y los canales de participación para ello desarrollados en la Castilla bajomedieval. Se trata, ciertamente, de una realidad compleja, cuyas expresiones, se antojan frecuentemente contradictorias, a primera vista, respecto al marco socio-político e institucional percibido por el historiador, pero que, en último término, obedecen a una lógica interna de las relaciones de esa elite social urbana articulada en distintas escalas y afectada por factores de tipo sociopolítico, económico, familiar, etc. En este sentido, la imagen de excepción ofrecida la documentación generada por un conflicto como el que pasaremos a tratar nos coloca ante una oportunidad excepcional de comprender las filiaciones políticas de estas elites locales y las problemáticas de conciliación de las diversas solidaridades de grupo en que se veían inmersas.

\section{LA VILLA DE PAREDES DE NAVA BAJO EL SEÑORÍO DE FERNANDO DE ANTEQUERA}

Con el fin de alcanzar una comprensión más clara de los fenómenos que vamos a exponer, conviene, en cualquier caso, presentar el espacio en que vamos a movernos en este trabajo. Para ello es más que necesario una somera pero eficaz contextualización geográfica del lugar, la presentación del entramado de instituciones con que contaba la villa, poniendo de relieve la conexión entre las estructuras sociales de la localidad y el acceso a aquellas

\footnotetext{
${ }^{5}$ Un repaso a la bibliografía citada en las notas 2,3 y 4 permite constatar cómo los estudios sobre la conflictividad política en el seno de las ciudades castellanas ha sido analizada, fundamentalmente, a partir de estos centros mayores bajo control de la Corona -Burgos, Valladolid, Salamanca, Avila, Segovia, Soria, Cuenca, Sevilla...- y en mucha menor medida sobre las informaciones referidas a los núcleos de tamaño medio o pequeño, mucho más numerosos y muy a menudo sujetos a diferentes formas de señorialización.
} 
y, además, un breve repaso a algunos de los hitos fundamentales de la historia de Paredes con anterioridad a su entrada en el señorío del infante don Fernando. Todo ello procede de cara a comprender de un modo más profundo los orígenes del hecho conflictivo que vamos a estudiar y sus implicaciones tanto en la vida política interna de este núcleo urbano como en sus relaciones con las instancias de poder superior a ella, particularmente la autoridad señorial. En cualquier caso, el grueso de las informaciones aquí referidas remiten a la tesis doctoral de Juan Carlos Martín Cea sobre esta villa en el siglo $\mathrm{XV}$, en la cual se hallan desarrolladas con un mayor detalle, y a otros trabajos que se han ocupado de esta villa como objeto de estudio. No obstante, convendremos a matizar o resaltar algunos aspectos de particular interés para la presentación del asunto historiográfico que vamos a abordar en estas páginas.

Paredes de Nava se encuentra a 17 kilómetros al noroeste de la ciudad de Palencia, situada en el extremo nororiental de la comarca castellana de Tierra de Campos. Más allá de tratarse de una simple villa al norte del valle del Duero, su alfoz, de unos $130 \mathrm{kms}^{2}$ era uno de los más importantes de la Tierra de Campos y el mayor de la actual provincia de Palencia ${ }^{6}$.

Las evidencias con que contamos nos permiten señalar que, en efecto, se trataba de un centro articulador del territorio de cierta importancia en el área oriental de la Tierra de Campos. Las escasas referencias documentales a Paredes anteriores al siglo XIV y, ante todo, las prospecciones realizadas en el término y recogidas en la Carta Arqueológica Provincial constatan la existencia de diferentes núcleos de población en el mismo, aldeas y pequeñas células de explotación agrícola de escasa entidad, en época alto y plenomedie$\mathrm{val}^{7}$. Sin embargo, los datos recogidos en el Becerro de las Behetrías entre 1350-1353 no informan de la existencia de ninguna aldea dependiente de la villa y la propia documentación municipal de finales del siglo XIV y todo el siglo XV confirma que éstas, efectivamente, habían desaparecido ${ }^{8}$. En efecto, para esas fechas el conjunto de la población se había concentrado en un compacto núcleo villano poderosamente amurallado y articulado en torno a ocho barrios, o collaciones, y cuatro parroquias ${ }^{9}$.

${ }^{6}$ España. Atlas e índices de sus términos municipales (2 vols.), Confederación Española de Cajas de Ahorros, Madrid, 1969 , Vol. I, pp. 167-171. Aunque el dato se refiere a la superficie del término municipal actual, la formación de los dichos términos tiene una base de origen histórico, fundamentalmente medieval, que permite su uso con valor aproximativo (Ver A.M. BARRERO, Los términos municipales en Castilla en la Edad Media en "Actas del $2^{\circ}$ Symposium de Historia de la Administración", Madrid, 1971, pp. 137-160).

${ }^{7}$ Juan Carlos MARTÍn CEA, El mundo rural castellano a fines de la Edad Media. El ejemplo de Paredes de Nava en el siglo XV, Valladolid, 1991, pp. 28-29.

${ }^{8}$ Gonzalo MARTÍNEZ DÍAz (ed.), Libro Becerro de las Behetrías. Estudio y texto crítico (3 vols.), León, 1981, Vol. I, pp. 331. Efectivamente, la documentạción concejil no menciona, implicita ni explícitamente, la existencia de aldeas sometidas a la jurisdicción de la villa. A lo largo del siglo XV el concejo procedería a la compra de algunas heredades circundantes débilmente pobladas, entre las que destacaría por su potencial económico y mayor volumen demográfico la de Villafolfo, anexada completamente en 1483 (J.C. MARTIN CEA, El mundo rural, pp. 106-110).

${ }^{9}$ ÍDEM, El mundo rural, pp. 29-32. 
Esta relevancia de Paredes de Nava se ve confirmada también por su potencial demográfico. Es verdad que entrar en precisiones para el cálculo de la población para épocas medievales es, cuando menos, delicado. Gracias a la conservación de series prácticamente completas de la contabilidad municipal de la villa desde 1388 a 1454 podemos reconstruir buena parte de los padrones confeccionados para la recaudación de impuestos directos reales y señoriales. En ellos, la unidad de tributación es el fumo o fumadgo. El número de fumos contabilizados entre 1400 y 1416, años del señorío del infante don Fernando sobre Paredes de Nava, oscila entre los 712 de 1404 y los 847'5 de 1407, con grandes oscilaciones hasta la década de 1410 , en que el número tendió a quedar estabilizado en los 771'5 y sólo a partir de mediados de siglo se situaría en torno a los 800 para superar esta cifra en el último cuarto del Cuatrocientos. Dentro de las dificultades de interpretación del concepto de fumo y la imposibilidad de equipararlo perfectamente con un hogar poblado por una familia, Martín Cea calcula para la primera mitad del siglo XV una población de 2.700 a 3.500 habitantes ${ }^{10}$. A ello habría que sumar todos aquellos individuos libres de pechos en Paredes por una u otra razón. No es sencillo calcular de cuántas personas más podríamos estar hablando pero acaso no sería descabellado hablar de una población total para el primer cuarto del siglo XV de entre 3.000 y 4.000 habitantes $^{11}$.

No obstante, gracias a la disponibilidad de un buen número de referencias de carácter diverso relativas a la comarca terracampina y más particularmente a la villa podemos aproximarnos a la importancia relativa de esta población en la primera mitad del siglo XV respecto a las de su entorno. Pese a la heterogeneidad de derechos recogidos en el Becerro de las Behetrías, en esta encuesta Paredes figura entre las villas que pagaban las cuantías más altas en la Tierra de Campos a mediados del siglo XIV, junto con Medina de Rioseco, Tordehumos, Cuenca de Campos, Aguilar de Campos (actual provincia de Valladolid), Ampudia, Urueña, Becerril de Campos (actual provincia de Palencia) o la propia ciudad de Palencia ${ }^{12}$. Por otro lado, ya en el momento histórico que nos ocupa, en 1409 el repartimiento en la merindad

\footnotetext{
${ }^{10}$ Ibídem, pp. 31-37.

${ }^{11}$ Es bien conocido que la demografía histórica para época medieval se halla limitada, entre otros factores, por la disponibilidad casi exclusiva de fuentes fiscales para estos fines de cálculo de la población. El manejo de unidades de tributación contabilizadas en un lugar exige tener en cuenta que éstas no eran estrictamente correspondientes con grupos familiares nucleares y que, por otro lado, tampoco tendrían una fácil traducción en un numero de individuos concreto por unidad. En esta posible contabilidad habría que valorar, por otro lado, el volumen de personas no recogidas en estos registros por diferentes razones de orden socio-económico: sujetos de condición nobiliaria, clérigos, hidalgos exentos, ballesteros del rey y pobres de solemnidad, y, salvando a los eclesiásticos, a sus familias, no obligados por la exacción fiscal, por no hablar de plausibles bolsas de población no avecindada que, a efectos tributarios, aparecerían recogidos en los padrones de otros centros distintos a aquel en que habitasen. Sobre los procedimientos de contabilización de estas unidades para la confección de padrones fiscales y las dificultades que implica su uso como fuente demográfica, aplicado al caso específico de Paredes de Nava, véase: "María Jesús FUENTE, Sobre pechos y pecheros de un concejo medieval. Paredes de Nava, "Espacio, Tiempo y Forma. Historia Medieval", 5 (1992), pp. 39-64; IDEM, Fuegos fiscales y fuegos reales. Paredes de Nava en el siglo XV, "En la España Medieval", 16 '(1993), pp. 83-89.

${ }^{12}$ G. MARTínEZ DíAZ (ed.), Libro Becerro, vol. 1, pp. 197-201, 204-205, 279, 285-286, 296297 y 331.
} 
de Campos de la mitad de los 40 cuentos, esto es, millones, de maravedís (mrs.) votados en concepto de servicio en las Cortes de ese año nos habla de cantidades de 31.732 mrs. para la ciudad de Palencia, 26.066 para Becerril, 23.200 para Villalón (actual provincia de Valladolid) y Ampudia con 18.000, que corresponderían a totales de 63.464, 52.132, 46.400 y 36.000 mrs., respectivamente $^{13}$. Paredes no figura en esta relación al pertenecer a la merindad de Carrión, pero sabemos que el servicio completo pagado al rey en ese año ascendió a $48.000 \mathrm{mrs}^{14}$. Mientras, en el servicio de 1462 sólo las ciudades de Burgos, Valladolid y Palencia fueron encabezadas con cuantías mayores que Paredes de Nava en todo el noreste de la cuenca del Duero ${ }^{15}$. Por tanto, la perspectiva ofrecida por estos datos nos permite constatar la importancia cualitativa que tenía este centro de población en una región densamente habitada y urbanizada como era la cuenca del Duero en los siglos bajomedievales.

Entiéndase, pues, manejando tanto datos cualitativos como cuantitativos, que nos podamos referir a un núcleo de tamaño medio-grande y de gran relevancia en la vertebración del espacio terracampino. En cualquier caso, hemos de reconocer que, desde el punto de vista económico, la villa de Paredes de Nava aparece como una población predominantemente agrícola y ganadera, en que las actividades artesanales y comerciales alcanzaban un desarrollo circunscrito casi estrictamente al ámbito local y comarcal más inmediato. Este hecho acaso resultaría comprensible dentro de una red de poblamiento jerarquizado, en que las funciones económicas de villas como ésta quedarían mediatizadas por la pujanza e influencia de ciertos centros mayores, particularmente la cercana ciudad episcopal de Palencia, en el caso que nos ocupa ${ }^{16}$.

En otroorden de cosas, conviene presentar igualmente el marco institucional en que se movía nuestra villa, dibujando a la par la estructura

\footnotetext{
${ }^{13} \mathrm{El}$ profesor Julio VALDEÓN BARUQUE utilizó esta fuente en un brillante trabajo sobre la población de la merindad de Campos (Fuentes fiscales y. demográficas. La merindad de Campos en la primera mitad del s. XV, "En la España Medieval", 1, (1980), pp. 579-591). No obstante, una detallada lectura de la carta real en que se detalla la cuantía del repartimiento permite comprobar como este pedido corresponde a 20 cuentos, primera mitad de un pedido total de 40 cuentos, por lo tanto, las cantidades finales encabezadas habrían de ser el doble. (Archivo Municipal de Villalón de Campos, Libro del Acuerdo $n^{\circ}$. 1, años 1404-1423, ff.. 15 v.-16 v., 1409-VIII-27, martes).

${ }^{14}$ Archivo Municipal de Paredes de Nava (AMPdN), Cuentas de Propios (CP), 238/11, ff..10/03 v.-04v., 1409.

${ }^{15}$ Carlos REGLERO DE LA FUENTE, El poblamiento del noreste de la cuenca del Duero en el siglo XV, "Hispania", 190 (1995), pp. 425-493.

${ }^{16}$ Sobre la estructura económica de la villa, J.C. MARTín CEA, El mundo rural, pp. 78-136. Nuestros conocimientos sobre la articulación del territorio dentro de la Corona de Castilla en la Baja Edad Media son todavía básicos. Cabe señalar el esfuerzo de J.Ma MọSALVO ANTÓN por apuntar una primaria jerarquía del poblamiento en el caso de las villas y ciudades de la Meseta Norte a partir de criterios de carácter esencialmente políticos [Centralización monárquica castellana y territorios concejiles (algunas hipótesis a partir de las ciudades medievales de la región castellano-leonesa), "Anales de la Universidad de Alicante, 13 (2000-2002), pp. 157-202]. No obstante, resulta indispensable atender igualmente a otros factores, particularmente aquellos de orden ecoonómico. Ello pasa ineludiblemente por la recomposición de las redes de producción y comercialización en torno a los centros rectores de estas actividades, labores en las que cabe destacar, entre otros, los trabajos de Hilario CASADO ALONSO sobre la ciudad de Burgos o los de María ÁSENJO GONŹÁLEZ y David IGUAL LUIS sobre la ciudad de Valladolid.
} 
social sobre la cual se sustentaba y el modo en que ambos se imbricaban, condicionando las formas de participación en el gobierno de la villa y de reparto del poder en la misma.

Un repaso a las instituciones y oficios del concejo de la villa permitiría distinguir su organización acorde con los rasgos definidos típicamente para el concejo cerrado bajomedieval castellano, en virtud a la implantación del sistema del regimiento y la consagración del control de las magistraturas por un selecto grupo de familias potentadas del lugar ${ }^{17}$. No obstante, hemos de tener presente que estos rasgos, más que definir un modelo, caracterizan una tendencia claramente oligárquica que, sin embargo, se desarrolla y plasma en cada caso local de un modo plural y heterogéneo respecto al resto ${ }^{18}$. De hecho, el sistema concejil paredeño en el siglo XV, pese a evidenciar esas características oligarquizantes, se veía condicionado por el referente gubernativo que seguían siendo sus ordenamientos forales, concedidos por Alfonso VII en 1128, 1129 y $1134^{19}$. Así, el concejo de Paredes de Nava estaba encabezado por un cuerpo de ocho onbres buenos, uno por cada collación que a partir de principios de siglo XV comienzan a ser denominados indistintamente por este nombre o por el de rregidores. Junto a ellos existían, fundamentalmente, cuatro alcaldes, uno por cada parroquia, encargados de la administración de la justicia, y dos procuradores responsables, de la gestión de la hacienda municipal, oficiales que en otras ciudades y villas era conocido con el nombre de mayordomos. Todos estos cargos eran electivos, si bien no conocemos bien cuál era el método seguido para su designación, en el que participaban los oficiales saliente, y todos ello, aún los de regidores, tenían una duración temporal de un año, a renovar tradicionalmente por Cincuesma, esto es, Pentecostés, en virtud de la conservación en vigor de las tradiciones forales de la villa. El cuadro se completaría con la presencia de un escribano de concejo, de carácter prácticamente vitalicio, dos merinos, al cargo de la ejecución de las penas de justicia, cuya detentación ponía el concejo en arriendo anualmente, y toda una serie de oficiales menores de diferente consideración ${ }^{20}$.

\footnotetext{
${ }^{17}$ Para una visión general respecto al regimiento Carlos ESTEPA DíEZ, Estado actual de los estudios sobre las ciudades medievales castellano-leonesas, en "Historia Medieval: cuestiones de

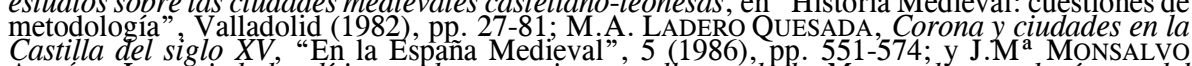
ANTÓN, La sociedad política en los concejos castellanos de la Meseta durante la época del regimiento medieval. La distribución social el poder, en Concejos y ciudades en la Edad Media hispánica, Madrid, 1990, pp. 359-413.

${ }^{18} \mathrm{~J}$.C. MARTín CEA; J.A. BONAChíA HERNANDO, Oligarquías y poderes concejiles en la Castilla bajomedieval. Balance y perspectivas, "Revista d'Historia Medieval", 9 (1998), pp. 23-
28.

${ }^{19}$ Los fueros de Paredes fueron editados, con ligeros errores, por Justiniano RODRÍGUEZ FERNÁNDEZ, Palencia (Panorama foral de la provincia), Palencia (1981), pp. 228-234. Años después, fueron objeto de transcripción parcial con el fin de revisar las incorrecciones citadas y de completar, a partir de copias posteriores, los fragmentos de texto perdidos en el documento más antiguo en que se han conservado los fueros (Carlos TRAVESí DE DIEGO, Pergaminos del Archivo Municipal de Paredes de Nava, Valladolid, 1996, pp. 12-17) 215 .

${ }^{20}$ Sobre el organigrama institucional del concejo, J.C. MARTÍN CEA, El mundo rural, pp. 188-
} 
Pese al vigor de la susodicha tradición foral paredeña y a la temporalidad de los principales oficios concejiles, el carácter oligárquico de este sistema de gobierno viene manifestado, tal y como expone Martín Cea en sus estudios sobre la villa, por la monopolización de los mismos por un número limitado de individuos unidos entre sí por ciertos lazos de parentesco y que ostentaban una posición socioeconómica elevada, diferenciada de la del resto de la población ${ }^{21}$. Un repaso a las nóminas de alcaldes, regidores, procuradores y merinos del concejo que se han logrado reconstruir con cierta fiabilidad, simplemente entre los años 1400 y 1430 , permite reconocer la recurrencia de ciertos "apellidos" en estos cargos: Tomás, Cabras, Harnueco, Hergujo, Berruguete, Lucas, Valiente, Cermenal, Serrano, Tajagrano,Garzón, Xarayo, Pelilla, Mazón, Moriscote, Rico... y algunos más. Se puede apreciar la presencia en estos listados de individuos, ciertamente, emparentados entre sí, a veces de un modo presumible, otras perfectamente documentados como tales. Por otro lado, también se observa la circulación de algunos de estos personajes de unos oficios a otros a lo largo del tiempo. El carácter de las fuentes paredeñas de la época, consistentes casi exclusivamente en las series de la contabilidad municipal, muy escuetas y sucintas en sus informaciones, dificulta enormemente la posibilidad de reconstruir los vínculos que unían a estos individuos. Esto es, en definitiva, de reconocer grupos familiares y otras posibles formas organizativas propias de la elite paredeña y de desentrañar el funcionamiento interno de tales estructuras de cara a la participación en el poder concejil. Aunque resulta francamente complicado concretarlo, todo apunta a que este sector que controlaba el concejo estaba formado exclusivamente por caballeros y escuderos fijosdalgos, jurídicamente privilegiados, celosos de compartir su primacía frente a pecheros enriquecidos y nuevos hidalgos. En cualquier caso, es palpable la existencia de este bloque oligárquico y la relación directa entre control del concejo y una preponderancia socioeconómica.

Valgan como ejemplo de ello las referencias obtenidas del alarde celebrado en 1409 por orden del infante don Fernando. De acuerdo con los ordenamientos de Cortes que regularon las reformas militares castellanas puestas en marcha entre 1385 y 1390 , tras la derrota de Aljubarrota hasta la promulgación del Ordenamiento de Lanzas de las Cortes de Guadalajara, el servicio en las tropas concejiles de las poblaciones urbanas quedaba determinado por la cuantía de las haciendas de cada uno de los individuos obligados a la prestación militar. Así, cada individuo era encuadrado en diferentes categorías de tropa según las diferentes calidades económicas y estaba obligado a mantener el equipo adecuado a la misma. Precisamente, las gentes

\footnotetext{
${ }^{21}$ Sobre la sociedad paredeña y el acceso diferenciado al gobierno urbano, ibídem, pp. 137-144 y 220-223. Posteriormente, este mismo autor procedió a una reordenación de las ideas expuestas al respecto, presentadas de un modo más sintético pero también más depurado y librado de ciertas incorrecciones interpretativas en la clasificación del grupo social dominante en la localidad (J.C MARTín. CEA, Poderes públicos y sociabilidad local en la villa de Paredes de Nava en el Cuatrocientos, en J.A. BONACHÍA HERNANDO (coord.), La ciudad medieval, pp. 255-316, en concreto, pp. 267-269 y 289-290.
} 
mejor abonadas quedaban señaladas para el servicio como caballeros armados a la guisa, jinetes y ballesteros bien equipados ${ }^{22}$. La nómina de esta revista de armas muestra, en fin, que la mayoría de los individuos que accedieron a los oficios concejiles, u otros que detentan alguno de los "apellidos" identificables de la lista que hemos citado anteriormente, se presentaron en esta revista de armas aguisados como caualleros, como vallesteros o como dezenarios de cada una de las cuadrillas de la milicia local. Es decir, dentro de los cuerpos más destacados de la misma o como sus mandos, en una correspondencia directa entre categoría militar, posición social y participación en los órganos del poder municipal ${ }^{23}$.

Fuera de esta elite local, los perfiles del resto de la población cristiana, el común, resultan difíciles de precisar, al menos en términos de participación política. De nuevo, las características de la documentación disponible complican su diferenciación interna. Pese a ello, se vislumbra la existencia de grupos de labradores ricos, propietarios medianos y pequeños y trabajadores agrícolas dependientes y por cuenta ajena, en cuanto a población campesina, estratificada a partir de un desigual acceso a la tierra, un cierto número de personas dedicadas a actividades artesanales y de pequeño comercio y, por último, pobres y marginales ${ }^{24}$. Apenas podemos detallar de qué modo se canalizaba la participación en la política concejil del común, aunque sí es cierto que, por otro lado, existen indicios a lo largo del siglo XV del rechazo por parte de la elite local hacia aquellos individuos que, a causa de su bonanza económica, pretendían acceder a la condición de hidalguía e integrarse en el grupo dirigente. Esto es, una oposición por parte del grupo dirigente de los caballeros hacia la competencia política que planteaban los sectores más encumbrados del común ${ }^{25}$.

El panorama socio-institucional de la villa quedaría completado al apuntar la presencia de otros dos elementos relevantes que caracterizaban la vida paredeña en los años en los que nos moveremos en este trabajo. Por una parte, la agrupación de la clerecía paredeña en torno a un cabildo fundado en

\footnotetext{
${ }^{22}$ Sobre los ordenamientos militares culminados en el de Guadalajara de 1390, Juan Carlos DOMÍNGUEZ NAFRÍA, Administración militar en la Edad Media: Las "Ordenanzas Militares" de Juan I de 1390, en "Quintos Estudios de Frontera: Funciones de la red castral fronteriza”, Jaén, 2004 , pp. 137-146. En relación con las milicias concejiles castellanas en época bajomedieval, existen múltiples trabajos de alcance local, si bien no contamos con una obra de síntesis que enlace con la de James F. PoWERS, A Society Organized for War. The Iberian Municipal Militias in the Central Middle Ages, 1000-1284, Berkeley-Los Angeles-Londres, 1998. En general, sobre los ejércitos bajomedievales castellanos, M.A. LADERO QUESADA, La organización militar de Castilla en la.Baja Edad Media, en Castillos medievales del reino de León, León, 1990, pp. 1134; Miguel Ángel BENITO RODRÍGUEZ, Estructuras y organización del ejército Trastámara. Aproximación a la historia militar castellana en la Baja Edad Media, "Revista de Historia Militar", 78 (1995), pp. 15-42. Para una revisión bibliográfica actualizada para el siglo XIV castellano, Francisco GARCİA FITZ, "Las guerras de cada día" en la Castilla del siglo XIV, "Edad Media. Revista de Historia”, 8 (2007), pp. 145-181.

${ }^{23}$ Sobre el alarde, J.C. MARTÍN CEA, El mundo rural, pp. 138-142. El documento, que contaba con la antigua signatura "Carpeta $3, \mathrm{n}^{\circ} .5$ ", hoy no se halla en el Árchivo Municipal de Paredes de Nava y, de hecho, no es citado en él catálogo realizado después de la última organización del archivo en los años 90 del pasado siglo XX.

${ }^{24}$ Ibídem, pp. 148-154.

${ }^{25}$ Ibidem, pp. 142-144 y 161-162.
} 
1329, organismo que le permitía sostener una notable organización interna para la defensa de sus intereses ante el concejo, y ante otras autoridades, laicas y eclesiásticas, incluidos su mismo superior, el obispo de Palencia, o la propia Corona. Por otro lado, que hasta 1412, momento en que se produjo su conversión, en Paredes floreció una considerable comunidad hebrea, organizada alrededor de su propia aljama. Aunque los datos sobre estos judíos son muy escasos, dan lugar a documentar algunos individuos, de apreciable relevancia a causa de sus negocios de crédito y arrendamiento de impuestos y que, tras la conversión, intentarían acceder al gobierno del concejo ante la frontal oposición de las viejas familias dominantes ${ }^{26}$.

La caracterización de este pequeño pero complejo sistema urbano adquiere, por último, su sentido más pleno al ponerlo en relación con las instancias de poder que, externas al mismo, concurrían en él y afectaban a su desarrollo interno. Aunque cabría entrar a considerar la influencia ejercida por elementos de tan diversa naturaleza como las estructuras organizativas de la Iglesia dentro del obispado de Palencia, al que pertenecía la villa, o los aparatos fiscales y territoriales de la Monarquía en la merindad de Carrión y el Adelantamiento Mayor de Castilla, nos centraremos en señalar un aspecto ineludible y de notable trascendencia a la hora de acercarnos al análisis del conflicto que vamos a tratar: la vinculación jurisdiccional de la villa en torno a la pertenencia al dominio realengo y la implantación del poder señorial sobre ella.

Así, conviene tener en cuenta que Paredes de Nava, al contrario que un buen número de villas de cierta importancia al norte del Duero, no había sido una fundación real ni su desarrollo como centro urbano había estado vinculado a la acción de la monarquía castellano-leonesa. Al contrario, prácticamente desde sus orígenes hasta su integración en el estado señorial del infante Fernando de Antequera, había sido una villa señorial. Los fueros otorgados por Alfonso VII en 1129 la consagraban como tal y, a lo largo de las distintas vicisitudes políticas ocurridas en Castilla y León hasta el inicio del siglo XV, había sido casi ininterrumpidamente un lugar solariego en manos, sucesivamente, de los Lara, los Castro, los Haro, señores de Vizcaya, de Leonor de Guzmán y sus hijos habidos con el rey Alfonso XI, de nuevo de los últimos Lara y, finalmente, de diferentes familiares de los nuevos monarcas Trastámara. Sólo en contados momentos había ingresado en el realengo, particularmente en 1326, cuando Alfonso XI la incorporó a su señorío, prometiendo expresamente no enajenarla de él, si bien esta situación apenas duró unos pocos años, y en 1351, cuando Pedro I se la arrebató a Nuño de Lara y la mantuvo bajo dominio de la Corona hasta su muerte en Montiel en $1369^{27}$. Sin embargo, tanto el valor de la promesa regia, expresada

\footnotetext{
${ }^{26}$ Sobre los clérigos y el cabildo, ibídem, pp. 148-154, 240-251 y 256-259. En cuanto a la minoría judía, ibídem, pp 154-162 y 251-252; J.C. MARTín CEA, Los judios de Paredes de Nava: la desaparición de la aljama palentina en 1412 , en "Actas del I Congreso de Historia de Palencia", Vol. II, Valladolid, 1987, pp. 539-552.

${ }^{27}$ J.C. MARTÍN CEA, El mundo rural, pp. 37-45.
} 
en forma de documento, como la experiencia posterior de casi dos décadas de acomodo bajo la jurisdicción real habrían promovido una poderosa conciencia de pertenencia al realengo, de ser del Rey dentro de la comunidad política paredeña, evidenciada a lo largo de toda la segunda mitad del siglo XIV a partir de la actitud contraria del concejo ante la señorialización por parte de diversos parientes del Rey ${ }^{28}$. Nos referimos, en efecto, al conocido levantamiento de 1371 contra Felipe de Castro, cuñado de Enrique II y nuevo señor de la villa, que culminó con la muerte de este noble aragonés y la posterior represión desatada sobre el lugar pero, igualmente, al intento de la villa en 1393 de que Enrique III revalidase la condición realenga de Paredes, aprovechando el contexto de conflicto que enfrentaba al joven monarca con el partido liderado por sus parientes, la reina Leonor de Navarra, Alfonso conde de Noreña, y Pedro, conde de Trastámara, y la propia pugna entre estos dos últimos por el señorío de la villa ${ }^{29}$. Tanto la vinculación señorial como ese sentimiento realengo y, sobre todo, la propia identidad como comunidad única frente a poderes interventores externos que a la misma subyace han de ser valorados a la hora de interpretar las coordenadas en las que se movió el conflicto ocurrido en el seno de este sistema concejil entre 1401 y 1403 y la

\footnotetext{
${ }^{28}$ El vínculo que unía a muchas ciudades y villas castellano-leonesas de diferente condición y evolución histórica, tanto realengas como de señorío, con la persona del Rey y su autoridad fue críticas en los tiempos bajomedievales. Cabe destacar el afloramiento de este rasgo político comunitario ante situaciones de incertidumbre política general en el reino, de iniciativas señorializadoras o de acciones violentas de poderosos y malfechores mediante fórmulas de toma de partido y resistencia que tienden a confluị en la expresión de la defensa del servicio del monarca y del señorío regio. Estos elementos distintivos son ya observables en el tránșito del siglo XIII al siglo XIV tanto en el marco general del reino como en ámbitos regionales más singularizados. Buenos ejemplos de ellos podrían evidenciarse en casos de análisis territorial, por ejemplo en relación con las villas riojanas, (Pascual MARTínEZ SOPENA, El equilibrio roto, en José Ángel SESMA MUÑOZ, Historia de la ciudad de Logroño. Tomo II. Edad Media, Logroño, 1995, pp. 297-310, en particular, pp. 306-310), pero también asociados a movimientos de naturaleza, alcance y ámbitos de acción más amplios y complejos, como el caso del desarrollo de las Hermandades (para una revisión actualizada, Maria ASENJO GONZÁLEZ, Ciudades y hermandades en la Corona de Castilla. Aproximación sociopolítica, "Anuario de Estudios Medievales”, 27/1 (1997), pp. 103-146; César GONZÁLEZ MíngUEZ, Poder y conflictos sociales: una visión desde la historia del movimiento hermandino castellano, en José Antonio MUNITA LOINAZ (ed.), Conflicto, violencia y criminalidad en Europa y América. "IV Jornadas de Estudios Históricos del Departamento de Historia Medieval. Moderna y de América (Vitoria-Gasteiz, 11 al 13 de noviembre de 2002)", Vitoria (2004), pp. 13-37). La recurrencia de estos aspectos entre el final del siglo XIII y el siglo XV (véase, a modo de ejemplo, Paulino IRADIEL MURUGARREN, Formas de poder y de organización de la sociedad en las ciudades castellanas de la baja Edad Media, en VV. AA. Estructuras y formas de poder en la Historia, Salamanca (1991), pp. 24-49, en particular, pp. 29-33; o José Manuel NIETO SORIA, Fragmentos de ideología politica urbana en la Castilla bajomedieval, "Anales de la Universidad de Alicante", 13 (2000-2002), pp. 203229) aconsejarían una revisión pormenorizada de los mismos de cara a definir ese valor político urbano que fue en Castilla y ser del Rey y sus evoluciones e instrumentalizaciones por los agentes de la sociedad política castellana bajomedieval.

${ }^{29}$ Sobre el levantamiento contra Felipe de Castro, J. VALDEÓN BARUQUE, Los conflictos sociales, pp. 107-110; sobre el propio Felipe de Castro, María Teresa FERRER I MALLOL, Los descendientes de Ferran Sanxis de Castre, hijo bastardo del Rey, Jaime I El Conquistador (siglos $X I I I-X I V)$, "Hidalguía", 122 (1974), pp. 25-48, en concreto pp. 39-40. En cuanto al intento de reintegración en el reálengo en 1393, Victor MUÑZ GóMEZ, La adquisición de dominios señoriales en la Castilla Bajomedieval.' Fernando de Antequera y Paredes de Nava (1380-1408) en "III Simposium Internacional de Jóvenes Medievalistas. Lorca. 2006". Murcia, 2008, pp. 121132 , en concreto, pp. 122-126. Conviene recordar que, entre 1383 y 1385 , la villa volvio a ser realenga, como veremos.
} 
propia mediación resolutiva ejercida por el señor, el infante Fernando de Antequera. Dicho todo ello, procedemos a presentar el mismo ${ }^{30}$.

\section{BANDOS, CONFLICTO Y RESPUESTA SEÑORIAL. EL CONFLICTO DE 1401-1403}

Nos situamos en el año 1400, cuando, a la muerte del señor de la villa, don Pedro, conde de Trastámara, su hijo y sucesor don Fadrique procedió a trocar con el infante don Fernando y su esposa, Leonor de Alburquerque, Paredes de Nava por Ponferrada, Villafranca del Bierzo (actual provincia de León) y El Barco de Valdeorras (actual provincia de Orense), en el Bierzo y Galicia ${ }^{31}$. Este traspaso del señorío se ejecuto sin mayores contratiempo, a tenor de la documentación municipal, y fue en 1401 cuando una situación conflictiva latente se manifestó, precisamente en torno al nombramiento de los oficiales del concejo.

Ese año, la villa recibió al infante para su toma de posesión del señorío ${ }^{32}$. En el tiempo en torno a este acto, el concejo aprovechó para realizar las gestiones oportunas para elevar ante la Corte de don Fernando la petición de "...quel dicho conçeio nombrase los ofiçiales e non fuesen los que eran nombrados de vando a vando, e ganóse esta carta", con resultados, en efecto, positivos ${ }^{33}$. En efecto, parece que buena parte de la elite dirigente de la villa se organizaba alrededor de dos bandos y, hasta la fecha, había utilizado estas formas de agrupación para capitalizar y repartir los órganos de gobierno del concejo. Así, al calor del cambio de titularidad señorial, un sector de la población paredeña, presumiblemente no integrado en los dichos bando, se había movilizado para romper el monopolio de los oficios concejiles que ejercían estos grupos.

Sin embargo, esta iniciativa no fue, como se podía esperar, bien aceptada por los bandos, que igualmente se movieron ante la Corte del infante, solicitando su intervención para enmendar esta situación. Apenas

\footnotetext{
${ }^{30}$ Para una breve introducción al mismo, véase J.C. MARTÍN CEA, El mundo rural, pp. 48-53; ÍDEM, Poderes públicos, pp. 292-293; IDEM, Violencia y conflictividad social en Castilla, vista desde el prisma de la historia local (siglos XIV y XV), en J.A. MUNITA LOINAZ (ed.), Conflicto, pp. 129-130.

${ }^{31} \mathrm{~V}$. MuÑoz GómEZ, La adquisición de dominios señoriales.

${ }^{32} \mathrm{AMPdN}, \mathrm{CP}$, Borradores, 236/16, f. 62/03 r., 1401; CP, 238/03, ff. 02/03 r., 04 r., 06 v., 07 r.-08 r., 1401. Estas anotaciones en los libros de cuentas del concejo se refieren a gastos desprendidos en la recepción del infante Fernando de Antequera para la toma de posesion del lugar: mensajeros, derechos de entrada, festejos, etc.

${ }^{33} \mathrm{AMPdN}, \mathrm{CP}$, Borradores, 236/16, ff. 62/04 r., 07 r. y v., 13 v. 27 v., 56 r., 1401; Cuentas de Propios, 238/02, f. 01/01 r., s.a. [1401]; 238/03, ff. 02/06 v, 07 v., 09 v., 14 v., 1401. La falta dẹ data en las anotaciones contables paredeñas impide conocer en qué momento concreto del año el infante Fernando tomó posesión de la villa. Lo mismo ocurre con las gestiones para ganar esta provisión sobre el nombramiento de los oficiales concejiles. A ellas se refieren las anotaciones contables indicadas. Todo apunta a que las primeras reuniones del concejo sobre esta cuestión y la audiencia ante el infante sobre este negocio en Villalón, donde se ganó la carta, fueron previas a la visita del señor, y que el asunto quedó definitivamente despachado en la Corte de don Fernando en Medina del Campo después de la toma de posesión referida.
} 
conocemos los pormenores de estas gestiones pero sí sabemos que, al mismo tiempo, el concejo no permaneció ocioso y, en julio de 1402, envió a Juan García Tablares, uno de los procuradores, y a Juan García Mazón, probablemente uno de los alcaldes, ante el infante, volviendo éstos con una carta suya relativa a los oficiales de la villa ${ }^{34}$. Con independencia del contenido de la misma, que no se ha conservado, parece que la situación no se normalizó y, tras la presencia ese mismo mes de García de Cisneros y Gonzalo López, alcaldes del infante, en la villa ${ }^{35}$, el señor tomó la iniciativa de enviar un corregidor allí llegado el 28 de agosto de 1402: Sancho Fernández, el moço, vecino de Medina del Campo (actual provincia de Valladolid) y vasallo del infante $^{36}$. De nada sirvieron los requerimientos que el concejo había hecho al infante don Fernando para que diera marcha atrás en su decisión ${ }^{37}$. Su cometido era enmendar "... algunas cosas non deuidas, las quales son contra todo derecho e iustiçia”, con la potestad de nombrar para ello y de hacer pesquisa de la gestión de los oficiales del concejo pasados y presentes para remediar las irregularidades que se hubieran cometido. Éste fue inmediatamente acogido por los representantes de los bandos pero radicalmente rechazado por el concejo, no entendiendo ser conveniente a la justicia de la villa ni haberlo demandado el concejo sino los dichos bandos ${ }^{38}$.

Las reacciones no se hicieron esperar. El corregidor, tras recibir la negativa del concejo, el 29 de agosto de ese año, en virtud a la carta de nombramiento del infante y del recibimiento por parte de los bandos, a los que consideró la mayor parte de la población de la villa, suspendió los oficios de justicia del concejo y emplazó a éste ante la corte judicial de don Fernando ${ }^{39}$. Cuando el concejo de Paredes envió a Juan García Tablares y a Fernán Martínez, bachiller, alcalde de la villa, como sus emisarios a Medina del Campo ante el infante con peticiones sobre el corregidor, éste decretó su encarcelamiento, seguramente por el desacato a su mandado y, por otra razón, a causa de la suspensión en su oficio de que habían sido objeto por orden del

\footnotetext{
${ }^{34} \mathrm{AMPdN}, \mathrm{CP}, 238 / 04$, f. 03/06 r., 1402: asiento de 5 florines por la carta que trajeron sobre los oficiales Juan García Tablares y Juan García Mazón, en julio de 1402.

${ }^{35}$ AMPdN, CP, 238/04, f. 05 v., 1402: asiento de 60 mrs. para dar de cenar a García de Cisneros y Gonzalo López, alcaldes del infante, cuando se presentaron en Paredes.

${ }^{36}$ AMPdN, CP, 238/01, f. 90/05 r., s.a. [1402]-VIII-28: asiento del gasto realizado por el concejo ese día para convidar a comer al corregidor. Acto seguido, el concejo se reunio para concertar al respecto ciertas peticiones a enviar al infante Fernando.

${ }^{37} \mathrm{AMPdN}, \mathrm{CP}, 238 / 04$, f. 03/02 v., 1402: asiento de $103 \mathrm{mrs}$. gastados por el procurador Fernán García Cabras y un hombre con una mula que le acompaño en misión a Medina del Campo con la petición al infante de “...que non nos diese corregidor".

${ }^{38}$ AMPdN, Carpeta 01, no 50 (Signatura Antigua), 1402-VIII-28, lunes-VIII-30, miércoles, Paredes de Nava. Este documento, la copia conservada por el concejo de la respuesta dada al corregidor para no recibirlo en su oficio en la villa, se encuentra en paradero desconocido tras la últıma ordenación del Archivo Municipal de Paredes de Nava en los años 90 del pasado siglo XX. Quiero agradecer al profesor Juan Carlos Martín Cea que me haya facilitado la consulta de una copia reprográfica que él mismo pudo tomar del dicho instrumento.

${ }^{39}$ Ibídem. La carta de nombramiento, datada en Medina del Campo el 22 de agosto de 1402 , fue presentada por Sancho Fernández al concejo y se halla inserta en el documento anterior de respuesta.
} 
corregidor Sancho Fernández ${ }^{40}$. En vistas de la situación, el concejo cejó en su voluntad de sacudirse la presencia del corregidor. De hecho, recurrieron a su mediación, a la del alcaide de la fortaleza de Paredes por el infante, Alfonso Fernández de las Eras, y a la de algunos oficiales principales de la Corte de don Fernando, como su Camarero, Álvaro de Ávila, para gestionar la liberación de los presos ${ }^{41}$. Desde entonces y hasta el final de su mandato, el corregidor no tendría problemas para ejercer los cometidos para los que había sido nombrado ${ }^{42}$.

Sin embargo, la situación era mucho más problemática de lo que pudiera parecer. Más allá de la impugnación que los bandos paredeños pretendían realizar del nombramiento de los oficiales del concejo al margen de la actuación de estos grupos, lo que las fuentes permiten vislumbrar en el fondo es el propio enfrentamiento entre ambos partidos por el poder en la villa. Este conflicto se veía capitalizado por el impacto de los asesinatos de varios vecinos por don Fernando, uno de los hijos de don Alfonso, conde de Noreña, señor de Paredes de Nava entre 1372 y 1383, y la consiguiente animadversión de los parientes de aquellos hacia este personaje ${ }^{43}$. Precisamente, una vez el concejo acató la autoridad del corregidor, contamos con evidencias de las negociaciones emprendidas para lograr una avenencia entre los bandos pasaban por este punto: lograr un acuerdo entre los parientes ofendidos y don Fernando, hijo del conde de Noreña ${ }^{44}$.

Durante los meses siguientes, las diferentes autoridades en Paredes de Nava, corregidor, concejo y bandos, entablaron sucesivas negociaciones con el fin de alcanzar un punto de entendimiento entre las partes ${ }^{45}$. Al tiempo, y probablemente en vistas a la dificultades existentes para alcanzar una concordia entre los bandos, tanto el corregidor como el concejo, a través del

${ }^{40} \mathrm{AMPdN}, \mathrm{CP}, 238 / 04$, f. 03/07 r., 1402.

${ }^{41} \mathrm{AMPdN}, \mathrm{CP}, 238 / 01$, ff. 90/05 v.-06 v., s.a. [1402]. Inicialmente, el concejo envió peticiones al infante y consiguió cartas del corregidor para el señor relativas a los emisarios apresados. Posteriormente, se procedió a ganar el apoyọ para su causa del camarero del infante y el alcaide del alcázar de Paredes para, finalmente, enviar una embajada formada por Fernando García, bachiller, Fernando Pérez, clérigo, Juan García Mazón, acaso uno de los alcaldes, y Alfonso Martínez dela Cavera, a don Fernando para solicitar la liberación de los encarcelados.

${ }^{42}$ Éstas no se limitaban a dirimir las disputas relativas a la participación en el gobierno de la villa y alcanzaban a cuestiones de tan diversa naturaleza como la mediación en pleitos, el control de los recursos fiscales, de las medidas de peso y capacidad usadas en ta localidad o el aprovechamiento de términos. Hemos tenido ocasión de trabajar con mayor profundidad en torno a las funciones de los corregidores señoriales en el estado señorial del infante Fernando de Antequera en un artículo reciente, al cual remitimos (V. MUÑOZ GóMEZ, Administración señorial y gobierno urbano durante los primeros Trastámara. Los corregidores del infante Fernando de Antequera y Leonor de Alburquerque (1392-1421) en "Actas del IV Simposio Internacional de Jóvenes Medievalistas. Lorca 2008". En prensa).

${ }^{43}$ AMPdN, CP, 238/04, f. 03/03 r., 1402: asiento de los gastos desprendidos por el concejo en la reunión mantenida con los parientes de los muertos para lograr que concedieran su perdon a don Fernando, hijo del conde de Noreña, y de ciertas peticiones elevadas posteriormente al infante Fernando.

${ }^{44}$ Ibídem; AMPdN, CP, 238/04, f. 03/08 r., 1402.

${ }^{45}$ Ibídem, AMPdN, CP, 238/05, f. 04/14 r., 1403: anotación relativa a los gastos devengados por la reunión desarrollada en las cuadras de Martín Alfonso, cura de Fernando, hijo del conde de Noreña, entre este don Fernando, el concejo y el corregidor para tratar el asunto del perdón de las muertes. 
procurador Pedro García, mantuvieron una intensa comunicación con el infante, en Medina del Campo, con el fin de que el señor, en virtud de sus funciones como justicia suprema sobre el lugar, interviniese favorablemente en la resolución del conflicto ${ }^{46}$. En cualquier caso, la tensión dentro de Paredes de Nava en torno a la propia lucha entre los bandos y la actividad del corregidor queda evidenciada por la presencia durante siete semanas de Pedro Fernández Cabeza de Vaca, vasallo del infante y regidor en la cercana villa Villalón ${ }^{47}$, otro de los centros del estado señorial de Fernando de Antequera y Leonor de Alburquerque, y sus hombres en la población, seguramente enviado por la autoridad señorial para atajar desórdenes ${ }^{48}$.

Tal como se puede apreciar, el infante Fernando no sólo permaneció puntualmente informado de la situación en su villa de Paredes, sino que fue particularmente reclamado para intervenir en la pacificación de sus vasallos y actuó en consecuencia para garantizar las condiciones necesarias para la asunción de acuerdos entre las partes enfrentadas. De hecho, al final sería su propia mediación la que sería recurrida para el logro de una concordia entre los bandos. Primero a través de una entrevista de todos los agentes locales implicadas en Palencia con el obispo de esta sede, Sancho de Rojas, acaso el más íntimo colaborador del infante castellano a lo largo de su vida, los días 26 y 27 de enero de 1403. En último término, y a resultas de estas vistas previas, mediante la comparecencia de las delegaciones correspondientes a don Fernando, hijo del conde de Noreña y al bando de los agraviados junto con ciertos representantes del concejo, el escribano del concejo Alfonso Fernández, el corregidor Sancho Fernández y el alcaide de la fortaleza, Alfonso Fernández de las Eras, ante la Corte del infante Fernando en Medina del Campo, entre el 1 y el 11 de febrero de 1403, fruto de la cual se firmó la concordia $^{49}$. Para nuestra desgracia, los documentos relativos a este acuerdo no se han conservado pero todo indica que sus términos fueron satisfactorios para ambas facciones. Así, poco después, resueltos los desórdenes y

\footnotetext{
${ }^{46} \mathrm{AMPdN}, \mathrm{CP}, 238 / 05$, f. 04/08 v . 1403: anotación relativa a al viaje realizados por una delegación, formada por Pedro García, hijo de Juan Alfonso, y por Domingo Fernández Galeano con Rodrigo Alvarez de la Serna, llegada a Medina del Campo para tratar las discordias dentro del concejo. AMPdN, CP, 238/05, ff. 04/19 r., 20 r., 23 v.: anotaciones correspondientes a gastos realizados por el procurador Pedro García y por el corregidor a cuenta del concejo para gestionar esta posible concordia con el infante. Sin embargo, los gastos relativos a estas ạctuaciones bien podrían corresponder al viaje poșterior en que se selló la concordiạ, aunque no invalidan nuestra afirmación acerca de la existencia de comunicación entre al autoridad senorial central, sus oficiales en la villa y el propio concejo alrededor del asunto que nos ocupa.

${ }^{47}$ AM Villalón, Libro del Acuerdọ n ${ }^{0}$. 1, años 1404-1423, ff. 20 v.-21 v., 1409-X-23, miércoles. En esta rẹnión del concejo de Villalón, Pedro Fernández aparece consignado como uno de los regidores del concejo y vasallo de infante en ese año y, junto al resto de los allí citados, al menos desde 1401 .

${ }^{48} \mathrm{AMPdN}, \mathrm{CP}, 238 / 05$, f. 04/23 v., 1403: anotación correspondiente a los gastos desprendidos por el concejo para el alojamiento de Pedro Fernández Cabeza de Vaca y sus hombres durante las dichas siete semanas.

${ }^{49}$ AMPdN, CP, Borradores, 236/18, ff. 64/10 r.-13 v., 19 r.-23 v., 1403; CP, 238/05, ff. 04/19 r., 22 r., 29 r.-39 r., 1403: apuntes contables relativos a los gastos desprendidos en los susodichos viajes y reuniones, con especial atención a la $238 / 05$, ff. $29 \mathrm{r} .-39 \mathrm{r}$, correspondiente a un cuaderno independiente de la contabilidad del negocio, iniciado el 25 de enero con la recepción de los dineros necesarios para los pagos a ejecutar y finalizado el 14 de febrero con el retorno de los últimos comisionados del concejo desde Medina del Campo.
} 
considerándose finalizados los cometidos para que había sido nombrado el corregidor Sancho Fernández, éste concluyó su mandato y abandonó la villa entre evidentes muestras de agradecimiento del concejo de Paredes de Nava ${ }^{50}$.

Este sería, a partir de las fuentes conservadas, un relato pormenorizado de los acontecimientos acaecidos alrededor del conflicto entre bandos que se vivió en Paredes de Nava entre 1400 y 1403, desde el momento en que se evidenció hasta su apaciguamiento. Anteriormente este enfrentamiento local ha sido objeto de atención historiográfica en distintos trabajos del profesor Martín Cea, inclusive desde la perspectiva de la conflictividad social, si bien siempre como un hito más dentro de las dinámicas sociopolíticas de este pequeño centro urbano en su contexto castellano bajomedieval ${ }^{51}$. Partiendo de esta base, conviene que procedamos a profundizar en ellos, ya que, por la propia relevancia de estos hechos históricos, nos será posible sumergirnos en los problemas que planteábamos al inicio de este trabajo.

\section{EN LAS RAÍCES DEL CONFLICTO: \\ FACCIONES, SOLIDARIDADES Y CONCURRENCIA DE INTERESES}

La relación de los acontecimientos presentada nos dibuja, efectivamente, una lucha entre los bandos en que se agrupó la elite social de la localidad palentina por el control del poder político en el concejo de la villa. Como planteábamos previamente, parece que, con anterioridad al acceso del infante don Fernando al señorío de Paredes de Nava, dos parcialidades habían copado los oficios del concejo, repartiéndolos entre ambas partes. Que el cambio de titularidad señorial dio pie a intentar subvertir esta situación de equilibrio entre estos dos partidos y de superioridad respecto a otros agentes socio-políticos de la villa. Que ello, finalmente, desembocó en un enfrentamiento entre estos dos grupos de la elite local y otro hipotético sector de individuos de la misma no alineados, que habrían accedido al gobierno concejil aprovechando la coyuntura del momento. Que esta lucha habría alcanzado sus extremos más sangrientos en forma de varios asesinatos, responsabilidad de don Fernando, hijo de don Alfonso, conde de Noreña, quien vendría a ser el líder de una de estas facciones. Finalmente, que sólo una intensa y decisiva intervención de la autoridad señorial del infante Fernando habría permitido la pacificación de la villa y un acuerdo entre los contendientes enfrentados, gracias, fundamentalmente, al envío de un corregidor a la villa y de la promoción de una concordia firmada por los

\footnotetext{
${ }^{50} \mathrm{AMPdN}, \mathrm{CP}, 238 / 05$, f. 04/18 r., 1403: asiento de $2.000 \mathrm{mrs}$. que se entregaron a Sancho Fernández, el moço, como regalo "por el vien que fizo aesta villa por la poner en paz". Las últimas menciones a este personaje no son posteriores a febrero de 1403, a la propia concordia y a la liquidación de su salario y el almoneda de los ajuares de las posadas que el concejo dispuso para el corregidor (AMPdN, CP, 238/05, ff. 04/12 r. y v., 14 r., 1403).

${ }^{51} \mathrm{~J}$.C. MARTÍN CEA, El mundo rural, pp. 48-53 y 253-254; ÍDEM, Poderes públicos, pp. 28283 y 292-293; IDEM, Violencia y conflictividad, pp. 129-130.
} 
bandos en su Corte. A grandes rasgos, esta sería la reconstrucción que Martín Cea ha realizado del conflicto que nos ocupa ${ }^{52}$.

No obstante, pese a la elaboración de un relato de los hechos y a la explicación de ellos que se nos muestra, en principio, una observación detenida del objeto de estudio nos sitúa ante un panorama lleno de puntos oscuros. Realmente, a tenor de la documentación disponible para ello, procedente del Archivo Municipal de la villa, podríamos afirmar que sabemos realmente poco respecto a los pormenores de este enfrentamiento. En este sentido, la mayoría de las informaciones recopiladas sobre estos acontecimientos procede de las anotaciones contables del concejo. Por desgracia, los cuadernos de cuentas del concejo de Paredes de Nava anteriores a 1404, conservados desde 1386, presentan un carácter a menudo fragmentario, amén que la ordenación diacrónica de los mismos no siempre es sencilla, como en el caso de los que nos interesan especialmente en este trabajo, de los años 1401 a 1403. La concisión de las anotaciones relacionadas a los gastos e ingresos de la hacienda concejil, por otro lado, a menudo siquiera datadas, dificultan su uso historiográfico, lo cual se ve agravado por la carencia de otros tipos documentales producidos o recibidos por el concejo de Paredes de Nava, que, nos consta, habrían aportado valiosas noticias para el análisis del conflicto que nos ocupa ${ }^{53}$. De ahí que, a partir de una ardua labor de puesta en relación cronológica y temática de los materiales disponibles, a la hora de abordar nuestro objeto de estudio, apenas podamos trazar un correlato de acontecimientos sin grandes detalles, ni siquiera en cuanto a las fechas en que se produjeron los principales hitos del enfrentamiento y su proceso de resolución. Convengamos pues que, habiendo de ser todo ello la base de nuestro conocimiento analítico, ésta no deja de ser mínima. No obstante, a partir de estas limitaciones, sí estamos en condiciones de profundizar con mayor concreción en algunos de los elementos clave del conflicto, como los protagonistas del mismo, o los motivos por los cuales pugnaron abiertamente

\footnotetext{
${ }^{52}$ Ibídem.

${ }^{53}$ La consulta de los distintos inventarios antiguos del archivo de 1820, 1847 y $1943-1945$ y de las propias referencias a las fuentes del mismo analizadas por Martín Cea para la elaboración de su tesis doctoral nos permite apreciar, más allá de una selección de los fondos que el concejo, a lo largo de los siglos, decidió conservar o expurgar por diferentes motivos que se nos escapan, otra reălidad más dramática para el historiador. En efecto, en el lapso transcurrido entre los comienzos del siglo XIX y los del siglo XXI, una buena parte de los instrumentos medievales que se habían custodiado en el archivo municipal han desaparecido sin que haya una razón clara pạra ello. Hemos de lamentar que la época que va desde 1945 hasta el día de hoy no haya sido particularmente la más afortunada en este sentido. Así, por una causa u otra, no podemos contar con libros de actas concejiles, privilegios, instrumentos judiciales, correspondencia, etc. de la época que aquí nos incumbe y que, en algunos cașos, tenemos constancia por esos inventarios citados o por el acceso a algunas referencias y copias que nos ha facilitado muy amablemente el profesor Martín Cea, de que existieron y, como señalábamos, podían ofrecer testimonios de primer orden en relación a las cuestiones aquí abordadas. Sobre los antiguos inventarios del Archivo Municipal de Paredes de Nava, véanse AMPdN, 10026/03, el de 1820, y AMPdN, 10026/08 y 09, los de 1943-45. Por su parte, de 1847 se ha conservado un curioso índice de los documentos que la villa en aquellos momentos tenía cusstodiados en la iglesia parroquial de Santa Eulalia. Nos fue posible consultar una transcripción del mismo depositada en el Archivo Parroquial de Paredes de Nava. Respecto a las fuentes manejadas por Martín Cea; IDEM, El mundo rural, pp. 11-12, más especialmente, las notas 3 y 4 de esta obra.
} 
¿Qué sabemos, entonces, sobre los bandos, sus miembros, o la estructura de estas organizaciones? En lo tocante a los susodichos bandos paredeños, estamos lejos de hallarnos ante las agrupaciones altamente organizadas, fundadas sobre lazos de parentesco, pero sobre todo sobre otros de carácter suprafamiliar, como aquellos de clientela y afinidad política, y fuertemente institucionalizadas dentro de la vida municipal que existieron en otras ciudades de la Corona de Castilla en la Baja Edad Media con el nombre de linajes $^{54}$. Lo que sí es posible evidenciar es que, en situaciones concretas de conflicto interno dentro del concejo de Paredes, como la de 1402-1403 que estudiamos, o la posterior de 1423-1427, las fuentes nos remiten al término vando para definir a los partidos en pugna ${ }^{55}$. Pero, dentro de la documentación paredeña medieval, tanto en la anterior a 1401 como entre aquella que media entre 1403 y 1423 y la posterior a 1427 , fuera de esos contextos precisos de enfrentamiento, no hallamos referencias a estos vandos, ni tampoco a algún otro término que permitiera extrapolar la existencia de forma alguna de linaje que aglutinase a distintas familias de la elite local de cara a la participación preferente en la vida municipal. Ello condujo a Martín Cea a considerar que la polarización banderiza sólo respondió a hechos puramente coyunturales, sin que existiese ninguna durabilidad en estas estructuras ${ }^{56}$.

Con todo, aunque no se puedan rastrear elementos que denotasen la identidad propia de estos linajes dentro de la comunidad, aunque no existiera nunca nada parecido a un cabildo de caballeros fijosdalgos o una Casa de linajes que los agrupase frente al común, centrándonos de nuevo en el objeto de estudio que nos ocupa, no deja de ser significativo un hecho. Y es que, el propio texto que nos trae por primera vez a colación un motivo de fricción en torno al nombramiento de los oficiales del concejo por los bandos en 1401 "...quel dicho conçeio nombrase los ofiçiales e non fuesen los que eran nombrados de vando a vando, e ganóse esta carta..." - , implica que, si era necesario que cesase tal forma de control de la cooptación a los cargos municipales por unos bandos, éstos en verdad debían de existir desde algún

\footnotetext{
${ }^{54}$ La bibliografía en torno a estas entidades, linajes y bandos-linaje, en la Castilla bajomedieval es ciertamente abrumadora en lo tocante a cada uno de los casos concretos de muchas de estas ciudades. Por su propósito de caracterización general de las dichas estructuras, sus rasgos comunes y los problemas de definición que suscitan, remitimos al trabajo de J.M ${ }^{\text {' }}$ MONSALVO ANTÓN, Parentesco y sistema concejil. Observaciones sobre la funcionalidad política de los linajes urbanos en Castilla y León (siglos XIII-XV). "Hispania", 53/185 (1993), pp. 937-969; y los de Máximo DIAGO HERNANDO, El papel de los linajes en las estructuras de gobierno urbano en Castilla y en el Imperio alemán durante los siglos bajomedievales, "En la España Medieval", 20 (1997), pp. 143-177;. IDEM, Las corporaciones de caballeros hidalgos en las ciudades castellanas a fines de la Edad Media. Su participación en el ejercicio del poder local, "Anuario de Estudios Medievales", 36/2 (2006), pp. 803-838; y el de José Angel SOLÓRZANO TELECHEA, Linaje, comunidad y poder: desarrollo y consolidacion de identidades urbanas contrapuestas en la Castilla bajomedieval en Familia y sociedad en la Edad Media (siglos XII-XV) ("Aragón en la Edad Media. Sesiones de trabajo"), Zaragoza, 2007, pp. 71-94.

${ }^{55}$ Véanse, al respecto del uso del término vando en relación con el primer conflicto citado, las anotaciones contables del concejo de Paredes citadas en la nota 33 o el propio documento señalado en la nota 38 (hasta cinco menciones de este vocablo, como la siguiente: "...en rreplicando contra lo quelos delos dichos vandos dezían..."); respecto al segundo conflicto referido, J.C. MARTíN CEA, El mundo rural, pp. 56-62.

${ }^{56}$ ÍDEM, Poderes públicos, p. 292.
} 
tiempo más atrás. Así debía de ser por más que no se precise desde hacía cuánto esos dos partidos se habían repartido los oficios.

Lo que sí es mucho más claro es que el problema del faccionalismo dentro de la elite local en torno al control del concejo volvió a repetirse entre 1423 y $1427^{57}$, y que acaso en años posteriores siguió vivo. Esta afirmación puede deducirse a partir del regesto de un documento sin data alguna, hoy perdido, consignada en el inventario del archivo municipal confeccionado en 1820. Éste nos informa que, en algún momento, el concejo había realizado una ordenanza, aprobada por quien entonces fuera señor de la villa, por la cual la elección de los oficiales del concejo habría de realizarse, bajo juramento, en las casas del concejo, el día de Año Nuevo o su víspera, mediante la elección por los oficiales salientes de cuatro candidatos de cada barrio, aptos y no adheridos a ningún partido, para que, de entre ellos, se sortease cada una de las regidurías y los demás cargos. Pero que, pese a ello, esta normativa no había surtido los efectos deseados, que eran “...que no se hiciese la elección en Persona de Vando...", pues aún con el juramento no era extraño que no se hallase “...persona fuera de partido...”, por lo cual el concejo rogaba al señor de la villa que se revocase la ordenanza y “... pidieron licencia para hacer dicha elección en la forma que se egecutaba antes de arreglar la tal ordenanza"58. La falta de cualquier tipo de data y las dificultades de atribuir ninguna concreta a partir tan sólo de las anotaciones extraídas a principios del s. XIX a un documento hoy imposible de contrastar no habrían de hacer descartar el interés de esta prueba. Un testimonio que, precisamente, habiéndose podido redactar en algún momento entre finales del siglo XIV y el siglo XVI, colabora a soportar la, cuando menos, sospecha de que los bandos que pudieron existir en Paredes de Nava fueron construcciones menos efímeras de lo que aparentan.

Evidentemente, para poder afirmar esto con rotundidad serían necesarios argumentos mucho más poderosos. Si no la constatación de unos signos identitarios de estos bandos, como un nombre de linaje, un lugar de vinculación, algún símbolo externo, cosa que no hemos hallado en la documentación, cuando menos la identificación de ciertos individuos o familias a estos posibles partidos y la recomposición de unas redes de afinidad política dentro de la sociedad local. No escapa a nadie la dificultad de ejecutar este tipo de reconstrucciones prosopográficas en los ámbitos municipales, más aún cuando las fuentes a nuestro alcance no son todo lo sistemáticas como

57ÍDEM, El mundo rural, pp. 56-62; ÍDEM, Poderes públicos, pp. 291-298; ÍDEM, Violencia y conflictividad, pp. 130-132. Si bien el autor apunte a indicios de resistencia antiseñorial contra el infante don Juan de Aragón, hijo de Fernando de Antequera, el motivo mejor exteriorizado de las luchas de estos años fue, efectivamente, el dominio de los oficios, por más que las razones para el antagonismo entre los caballeros de la villa fueran más complejas, tal y como explicaremos más adelante.

${ }^{58} \mathrm{AMPdN}, 10026 / 03$, Inventario General del Archivo. 1820. F. 51, doc. 162. Véase Apéndice documental, $\mathrm{n}^{\mathbf{0}}$. 2 . 
sería deseable ${ }^{59}$. En el caso de Paredes de Nava, las características de las fuentes, casi exclusivamente los cuadernos de cuentas del concejo, hacen que esta labor resulte particularmente ardua y que pueda tener un alcance, desgraciadamente, limitado. Aún habiéndose conservado una serie bastante completa de esta contabilidad entre 1386 y 1454, la codificación que en esta última se realiza de los individuos, oficiales del concejo, vecinos de la villa e incluso otros ajenos a la localidad, no es todo lo precisa y sistemática que se requeriría para estos fines, limitándose habitualmente a los nombres de pila y patronímicos y obviando la mención de nombres de familia y de cognómenes personales o toponímicos. En estas condiciones, aunque sí puedan reflejarse en ocasiones algunos tipos de relaciones de parentesco entre individuos ( $x$, hijo de $y ; z$, cuñado de $y$, etc.), el investigador apenas cuenta con un mínimo de garantías metodológicas a la hora abordar con una cierta fiabilidad una reconstrucción básica de las familias de la elite paredeña, ni en un momento preciso ni mucho menos a lo largo de la secuencia temporal aportada por las fuentes ${ }^{60}$.

Téngase, por cuanto, que la posibilidad de recomponer las filiaciones políticas de las facciones paredeñas, no ya en la primera mitad del siglo XV, sino simplemente en el momento de 1400-1403 en que se desataron las pugnas que aquí estudiamos, es, no diré imposible, pero sí de una complejidad abrumadora. Con seguridad, sólo los representantes de cada bando que el 29 de agosto de 1402 recibieron al corregidor en la villa, Pedro García, merino, y Juan Fernández Cano, por un lado, y Fernán García Lucas y Pedro García, hijo de Toribio Fernández, por el otro, son claramente distinguibles como miembros de bando, ni siquiera como sus cabecillas ${ }^{61}$. Por otra parte, los

\footnotetext{
${ }^{59}$ Entre otras muchas obras, me gustaría destacar el artículo de Francisco de Borja AGUINALDE OLAIZOLA, La importancia de llamarse inglesa (Alternativas para la reconstrucción de familias pp. 91-129, más centrado en el contexto banderizo vasco; y el más reciente de María ASENJO GONZÁLEZ, Cuestiones de método en historia social: las oligarquías urbanas en Castilla en La prosopografía como método de investigación sobre la Edad Media."Aragón en la Edad Media. Sesiones de trabajo", Zaragoza, 2006, pp. 55-76, en el que se aborda el caso de las ciudades castellanas dentro de la reflexión general que en este volumẹn se pretende aportar sobre el uso del método prosopográfico para los estudios medievales ibéricos actuales.

${ }^{60}$ Lógicamente, los documentos de uso administrativo que han llegado a nosotros no fueron elaborados por los escribanos como fuente histórica futura ni con los criterios que el investigador actual requiere a ésta. Donde sus usuarios de la época no hubieron de hallar problema para reconocer a cada individuo registrado, el historiador se mueve con inevitable torpeza e inseguridad. Algunos buenos ejemplọs de las formas de identificación de personas comúnmente utilizadas en la documentación concejil paredeña pueden observarse en el instrumento citado en la nota 38 (AMPdN, Carpeta 01, n⿳亠丷厂 50 (Signatura Antigua), 1402-VIII-28, lunes-VIII-30, miércoles, Paredes de Nava), en la cita de los individuos presentes al acto en que el concejo se negó a acoger al corregidor Sancho Fernández: “....estando presentes Ferrant Martínez, bachiller, e Martín Garçía Morate, e Iuan Garcia, alcalldes enla dicha villa, e Ferrant Garçía Cabras, e Iuan Garçía Tablares, procuradores del dicho con[çeio], e Iuan Ferrnández dela ... iota, e Diego García Rromo, e Fernando Garçía, fiio de Ximón Pérez, e Alfonso Garçía Laso, e Ferrant Pérez fíio de Martín G[arçía], e Alfonso Garçía dela Vid, e Alfonso Garçía, escriuano, rregidores dela dicha villa, e Pero Garçía, merino, e Iuan Ferrnández Cano, e Ferrant Garçía Lucas, e Pero Garçía, fiio de Toribio Ferrnández, e otros omes buenos...".

${ }^{61}$ Ibídem: "E los dichos Pero Garçía merino, e Iohan Ferrnández Cano dixieron sobre el corregidor] . ... quele rresçebían por ellos e por [to]dos los otros que conellos querrían ser. [...] E otrosí, los dịchos Ferrant Garçía e Pero Garçia, por sý e por otros sus parientes e amigos que a ellos se quesiesen allegar, dixieron eso mesmo". Llamamos la atención sobre las referencias a "parientes, amigos y los otros que con ellos quisieran ser o que a ellos se quisieran allegar", para
} 
oficiales del concejo, que decidió no aceptar al corregidor, podrían considerarse no adscritos a bando, tal y como consideraría Martín Cea, pero esto no es más que una suposición, ya que no conocemos cómo se llegó a tal acuerdo en el concejo, si fue unánime o hubo voces discordantes de algún regidor o alcalde vinculado a alguno de los partidos ${ }^{62}$. De hecho, a partir de toda la documentación que hemos consultado, casi ningún personaje más puede ser ubicado como miembro de una de las facciones con seguridad.

Ni siquiera los alcaldes Juan García Tablares y a Fernán Martínez, bachiller, que el concejo envió ante el infante a Medina del Campo y fueron apresados, pueden ser identificados como no adscritos a bando con todas las garantías, ya que, como recordaremos, el objeto de su misión era replicar el envío del corregidor a la villa y lo que el concejo pretendía era defender la legitimidad de sus oficiales frente al secuestro de los cargos de justicia que, ante el rechazo, el corregidos Sancho Fernández había realizado ${ }^{63}$. Si se me permite, aunque puede ser lógico identificar esta oposición al corregidor, apoyado por dos bandos, con una no pertenencia a ninguno de ellos, ello no lo convierte en la única respuesta posible, pudiendo encubrir un marco de fidelidades más complejo.

A decir verdad, es don Fernando, hijo del conde de Noreña, el individuo que parece mejor vinculado a uno de esos bandos, precisamente en una posición de liderazgo. Si la pugna por el nombramiento de los oficios del concejo alcanzó un punto de inflexión con el envío del corregidor señorial y su efectivo establecimiento en la villa, tras ese momento no hemos hallado referencias expresas al asunto de los cargos concejiles. La presencia del corregidor Sancho Fernández en Paredes de Nava y la finalización de su cometido en febrero de 1403 se vincula más bien al problema de los asesinatos de que era responsable este don Fernando y la consecuente enemistad hacia él de los parientes de las víctimas, finalmente zanjado en el marco de la concordia sellada en Medina del Campo en la Corte del infante. Martín Cea entendió, precisamente, que existía una conexión entre ambas formas de desorden, lo que le llevó a considerar a Fernando, hijo del conde de Noreña, como cabeza de uno de los bandos ${ }^{64}$. Probablemente, porque este investigador comprendió la estancia del corregidor como eje conductor del relato del conflicto y como nexo entre dos situaciones diferentes, enfrentamiento por los oficios concejiles y oposición entre el causante de ciertas muertes y los

caracterizar a los individuos adscritos a las parcialidades, en tanto refieren distintas formas de vínculos personales entre los dichos coaligados en bandos.

${ }^{62}$ Ibídem. La respuesta dada por los oficiales concejiles citados en la nota 60 , en bloque, sólo toca a su oposición al corregidor, al entender ser esto contra los fueros de la villa: "El dicho conçeio, alcalldes e omes buenos, en dando rrespuesta ala carta del dicho sennor infante, dixieron... que era de obedesçer e non de cumplir, e por quanto < dixieron $>$ que era e es agrauiada e dada contra derecho común e contra la ley rreal e contra los preuilleios desta villa".

${ }^{63} \mathrm{AMPdN}, \mathrm{CP}, 238 / 04$, f. 03/07 r., 1402. En efecto, tras la negativa del concejo a recibirlo, el corregidor Sancho Fernández "...por quanto el dicho sennor infante le diera poderýo del dicho corregimiento e iuzgado por su carta, por la qual carta priuara atodos los alcalldes que auían seydo e eran enla dicha villa e la villa quedaua sin iustiçia.." (AMPdN, Carpeta 01, no. 50 (Signatura Antigua), 1402-VIII-28, lunes-VIII-30, miércoles, Paredes de Nava).

${ }^{64}$ J.C. MARTÍn CEA, El mundo rural, pp. 49-50 y 254; ÍDEM, Poderes públicos, pp. 292-293. 
agraviados por ellas, que, desgraciadamente, en la documentación no aparecen explícitamente unidas pero podrían hallarse plausiblemente entrelazadas.

Lo que podría considerarse una deducción lógica a partir de pruebas no demasiado firmes se ve, no obstante, reforzado al comprobar la intrincada relación de don Fernando con la villa en las décadas anteriores. Efectivamente, su padre, Alfonso Enríquez, conde de Noreña y Gijón, había sido señor de Paredes entre 1372 y 1375 y de nuevo entre 1377 y 1383 , cuando el rey Juan I le desposeyó de sus títulos y estados y mandó encarcelarlo. Entregada la villa por Juan I a su pariente, Pedro Enríquez, conde de Trastámara, en 1386, el conde de Noreña, tras ser perdonado por el nuevo monarca, Enrique III, y restituido en sus bienes en 1392, no renunciaría a recuperar Paredes, en manos de su primo, el conde de Trastámara. Así, ocuparía por la fuerza el lugar, tal y como don Pedro denunciaba al rey en verano de 1394, en el contexto del enfrentamiento contra el rey de sus parientes coaligados - la reina Leonor de Navarra, don Fadrique, duque de Benavente, los condes de Noreña y de Trastámara y el infante don Joao de Portugal, además del arzobispo de Santiago Juan García Manrique -, una vez que el conde don Pedro decidió abandonar a sus aliados y encomendarse al monarca ${ }^{65}$. La derrota final del conde de Noreña y su exilio en Francia en 1395, donde se pierde la pista sobre sus últimos años de vida ${ }^{66}$, no supuso la desvinculación de su familia de la villa sino que, por el contrario, en los años siguientes su hijo don Fernando habitó frecuentemente en Paredes, adquiriendo una notable influencia en ella. De hecho, pese a que el señorío de la villa correspondía al conde de Trastámara, entre 1396 y 1398 don Fernando desarrollaría una serie de comportamientos relativos al concejo que verdaderamente suponían una flagrante apropiación de las prerrogativas señoriales por su parte. Así, en 1396 recibió del concejo 20.000 mrs. correspondientes al pedido de ese año, además de regalársele una mula ${ }^{67}$. En 1397 recibió otros 12.000 mrs., por adelantado, a cuenta del pedido, que inicialmente se comprometió a restituir

${ }^{65}$ J.C. MARTÍN CEA, El mundo rural, pp. 46-48; V. MUÑOZ GÓMEZ, La adquisición de dominios señoriales, pp. 121-132 especialmente las pp. 124-126. Sobre el conde de Noreña, véase Juan URÍA MAQUA, El Conde Don Alfonso, "Asturiensia Medievalia”, 2 (1975), pp. 177237, en concreto, 198-200. Respecto a don Pedro, conde de Trastámara, véáse Eduardo PARDO DE GUEVARA Y VALDÉS, Un ejemplo de la nueva nobleza trastamarista. El condestable Don Pedro Enríquez, "Anuario de Estudios Medievales", 14 (1984); artículo ampliado en su obra posterior dedicada a los condes de Lemos, Los Señores de Galicia. Tenentes y condes de Lemos en la Edad Media, 2 vols., A Coruña, 2000, pp. 201-250.

${ }^{66} \mathrm{~J}$. URÍA MAQUA, El Conde, pp. 232-237.

${ }^{67} \mathrm{AMPdN}, \mathrm{CP}$, Borradores, 236/11, ff. 57/06 r., 57/17 v., 1396. Los cuadernos recogidos bajo la signatura 236/11 son particularmente confusos y de procedencia y cronología dispar. Algunos de los pliegos que manejamos para estas referencias remiten específicamente a la contabilidad del escribano del concejo por sus servicios durante de los años 1396 y 1397; otros, a las cuentas de los procuradores, presumiblemente de 1396.

Por otra parte, tenemos constancia de que don Fernando y su hermana doña Constanza, fueron agasajados con 60 y 6 cántaras de vino, respectivamente, a modo de presente de Navidad. No obstante, al recogerse esta noticia en los borradores del año 1394 con anterioridad a la Cincuesma de ese año, cabe la posibilidad de que estos presentes se entregaran para la Navidad de 1393 y correspondieran al momento en que el conde Alfonso de Noreña tenía usurpada la villa. No obstante, denotan la posición de sus vástagos como representantes de su autoridad y dan una primera idea sobre la implantación de don Fernando en Paredes (AMPdN, CP, Borradores, 236/09, f. 55/38 v., 1394). 
o descontar de la cuantía del pedido de ese año ${ }^{68}$. Este menoscabo de los derechos de don Pedro, que no hemos hallado que recibieran ningún tipo de respuesta por su parte, sólo se explica si tenemos en cuenta que, tras su rebelión y posterior sometimiento al rey, aunque el conde de Trastámara adquirió importantes mercedes en Galicia y logró imponerse al arzobispo de Santiago, su más encarnizado rival, hasta alcanzar una posición de hegemonía en este reino, como señala Pardo de Guevara ${ }^{69}$, con la plena aquiescencia de la Corona, el alcance de sus ambiciones se limitó a estos territorios, quedando completamente desplazado de los círculos del poder en la Corte ${ }^{70}$. Este desplazamiento, político pero también físico del centro neurálgico de la Monarquía en el valle del Duero, afectaría, pues, igualmente a su capacidad para ejercer su autoridad en el señorío más alejado del centro de sus estados, concentrados en torno a Galicia y daría pie a la resuelta actitud de don Fernando, bien asentado en Paredes de Nava.

No obstante, su prepotencia hubo de generar importantes oposiciones en la villa, ya que el concejo exigiría el cobro de los $12.000 \mathrm{mrs}$. que le había entregado, que don Fernando se resistió a pagar, lo cual condujo al concejo a denunciar la deuda ante el arzobispo de Toledo, negándose, por tanto, a reconocerlos como parte de un pedido que no estaba dispuesto a entregarle ${ }^{71}$. Los motivos de discordia, sin embargo, sólo se acentuarían aún más y, en 1398, el concejo envió como sus representantes a Toribio Fernández, clérigo, Pero García, hijo de Toribio Fernández, Rodrigo Alfonso, Juan de Mazuecos y Pero Cebada no ante el señor, sino al rey, acompañados por 8 hombres de armas del Adelantado, para reclamar justicia “...delo que tenía tomado don Ferrnando acada vno delos vecinos de Paredes más delo quel auían de dar de su derecho para lo mostrar al rrey e le querellar las syn rrazones que don Ferrnando fazía por los caminos amuchos ommes"72. La pesquisa realizada a fin de mostrar los agravios en que éste había incurrido implicó a 193 testigos, dándose muestra del profundo descontento existente entre los paredeños contra don Fernando ${ }^{73}$. Las dificultades de datación de los borradores de las cuentas municipales entre 1396 y 1398 entorpecen notablemente la reconstrucción de los hechos pero sí sabemos que, en esos años, el concejo requirió al rey el envío de un corregidor y, en efecto, les fue comisionado en $1398^{74}$. No obstante, la presencia del corregidor no apaciguó la hostilidad de don

${ }^{68}$ AMPdN, CP, Borradores, 236/11, f. 57/06 r., 1396.

${ }^{69}$ E. PARDO DE GueVARA Y VALDÉs, Los Señores de Galicia, pp. 236-243.

${ }^{70}$ José GARCía ORO, La nobleza gallega en la Baja Edad Media, Santiago de Compostela, 1981, pp. 21-23; Luis SUÁREZ FERNÁNDEZ, Nobleza y Monarquía: puntos de vista sobre la historia política castellana del $s . X V$, Valladolid, 1975 (2 ed. corregida y aumentada), pp. 82-85.

${ }^{71}$ AMPdN, CP, Borradores, 236/11, ff. 57/03 r., 05 v., 06 r., 1396.

${ }^{72}$ AMPdN, CP, Borradores, 236/13, ff. 59/01 r.-03 v., 06 r., 1398.

${ }^{73}$ AMPdN, CP, Borradores, 236/13, f. 59/13 v., 1398.

${ }^{74} \mathrm{AMPdN}$, CP, Borradores, 236/11, ff. 57/07 r., 17 v., 18 r., 1396; 236/13 f. 59/18 r., 1398. Anotaciones relativas a la petición del corregidor ante la Corte y al pago de su sueldo. Procedentes de las cuentas de procuración del concejo, resulta difícil establecer su exacta datación, si bien las correspondientes a la signatura 236/13 sí parecen corresponder a 1398. 
Fernando y las idas y venidas ante la Corte y la Audiencia continuaron hasta, finalmente, ganar, acaso en 1399, carta del rey prohibiendo la entrada de éste a cinco leguas de la villa ${ }^{75}$. Parece que don Fernando terminó por deponer su actitud ante estas medidas. Sería en 1400 cuando el concejo recuperaría los $12.000 \mathrm{mrs}$. inicialmente reclamados, al deducir esta cantidad del pago de las monedas del rey que la villa había de pagar ese año y que fueron libradas en el heredero del difunto don Pedro, el conde don Fadrique. Éste había asumido la deuda de don Fernando al adquirirle unas casas por tal cuantía, en lo que se antoja la búsqueda de una doble satisfacción hacia las dos partes anteriormente lesionadas en sus derechos: el señor legítimo y el concejo ${ }^{76}$.

Puesto que don Fernando estuvo involucrado en los sucesos ocurridos entre 1401 y 1403 en la villa, la relación con los acontecimientos de los años previos y una continuidad con respecto a ellos resulta evidente. Más allá de una palpable debilidad de la instancia señorial para hacer frente a la usurpación de sus atribuciones, los hechos de 1396-1400 denotan que, pese a la oposición del concejo, sostenida en un importante sector de la población perjudicada por este personaje, don Fernando había de disponer de un cierto apoyo dentro de la villa para imponer sus exigencias, para coartar a las autoridades locales y para, en último término, en una situación ya francamente desfavorable, alcanzar una forma de arreglo que no supusiese su desalojo de la localidad. La necesidad de una avenencia a la altura de 1402 entre él y los parientes de ciertos asesinados por su cuenta apunta hacia el decisivo peso político que conservaba en Paredes de Nava como para condicionar las relaciones entre las dos facciones que trataban de repartirse los oficios del concejo. Si no porque fuera el jefe de una de las parcialidades, sí porque estuviera íntimamente relacionado con algunos de los miembros más prominentes de, al menos, uno de ellos. Ello concuerda, al menos de un modo razonable, con la preexistencia de los bandos antes de 1401, que apuntábamos anteriormente, de modo que el sostenimiento en una opinión favorable hacia los intereses de don Fernando por una parte de la elite social paredeña pudiera ser un factor condicionante de la alineación en uno de estos partidos o en el otro de los individuos que aspiraban al acceso al gobierno urbano. Por tanto, convendríamos que la intuición de Martín Cea en este sentido puede ser correcta, lo cual se confirmaría al constatarse que don Fernando siguió interviniendo en la vida local en las décadas siguientes como para que, durante el conflicto local desarrollado entre 1423 y 1427, él mismo fuera uno de los jefes de las dos facciones ${ }^{77}$.

Para terminar, en cualquier caso, de determinar el carácter de los bandos paredeños, hemos de volver sobre el problema de la elección de los

${ }^{75}$ AMPdN, CP, Borradores, 236/14, f. 60/01, 1399: acudieron ante el rey y la Audiencia en Valladolid para ello Toribio Fernández, el corregidor, Juan su sobrino y Juan, sobrino de Toribio Fernández, y otro hombre del corregidor "...con otros que auían de nos acompannar por quanto rreçeláuamos de don Ferrnando".

${ }^{76} \mathrm{AMPdN}, \mathrm{CP}$, Borradores, 236/15, f. 61/01 r. y v., 1400.

${ }^{77}$ J.C. MARTÍn CEA, El mundo rural, p. 60, donde refiere una anotación de las cuentas municipales de 1424 que reza textualmente "...los de la otra parte del vando de don Ferrando...". 
cargos concejiles y la evolución del mismo. Con las reservas que podría plantear la dificultad de ofrecer datas claras, como planteamos anteriormen$\mathrm{te}^{78}$, las primeras reuniones del concejo sobre el nombramiento de los oficiales en 1401 y las gestiones para lograr que no se realizase de vando a vando, con la audiencia ante el infante del escribano Alfonso Fernández y su yerno Diego Alfonso Mazón, sobre este negocio en Villalón, donde se ganó carta al respecto debieron de ser previas a la visita del señor a Paredes de Nava para ejecutar la toma de posesión de la villa ${ }^{79}$. Igualmente, apuntábamos que el asunto no quedó cerrado hasta un posterior viaje de los representantes del concejo a Medina del Campo, en concreto de Diego Alfonso Mazón para tratar con el infante y sus alcaldes ${ }^{80}$. Pero, posteriormente, nuevos delegados, Juan García Tablares y el procurador Juan García Mazón volverían a comparecer en Medina para ganar del infante una nueva carta sobre los dichos oficiales del concejo ${ }^{81}$. Aunque este documento ya se había perdido en 1943, no así en 1820 y, de hecho, gracias de nuevo a un amplio resumen del mismo, podemos conocer la esencia de su contenido y el cariz de esta ronda de gestiones. Y es que, en ella, el infante don Fernando indicaba que, en un primer mandato ordenó que los oficiales del concejo se nombrasen de entre ambos bandos y, si éstos no se aviniesen, se eligiesen aquellos que no fueran de bando. Y si ya habían otorgado los oficios, que se volviese a repetir el nombramiento. Pero indica después que, tras esto, los de una facción se le habían querellado por haber quedado fuera en el reparto, incumpliendo la orden señorial. Por ello, tras la declaración ante él de sujetos de ambas partes sobre quiénes eran de cada una de ellas, decretó que, en cumplimiento del primer dictamen, se volvieran a nombrar todos los oficiales por mitades entre los dos bandos y que como tales fueran hasta Pascua del año siguiente. Todo ello fue cumplido por el concejo, si bien declarando ser contrario a los fueros de la villa, exponiéndose protestas de algunos de los oficiales nombrados de haber sido señalados por los testigos como de bando ante el infante sin serlo ellos realmente, y que, en efecto, “...todo lo cual harían ver para que les fuesen guardados sus Privilegios", siendo la data de esta junta del concejo de 9 de junio de $1401^{82}$. No parece que el concejo tomase ninguna medida para defender esos derechos y, como ya hemos visto anteriormente, sería a partir de la renovación de los cargos concejiles por la Cincuesma de 1402 que las diferencias entre bandos se reproducirían y, finalmente, el infante don Fernando optaría por la solución radical de enviar a su vasallo Sancho Fernández como corregidor.

\footnotetext{
${ }^{78}$ Véase nota 33. 07 v., 1401 .

${ }^{79} \mathrm{AMPdN}$, CP, Borradores, 236/16, f. 62/07 r. y v., 1401; C.P. 238/03, ff. 02/06 v. y

${ }^{80}$ AMPdN, CP, Borradores, 236/16, f. 62/04 r., 1401; C.P. 238/03, f. 02/09 v., 1401.

${ }^{81} \mathrm{AMPdN}, \mathrm{CP}, 238 / 02$, f. 01/01 r., s.a. [1401]; 238/03, ff. 02/09 v., 14 v., 1401.

${ }^{82} \mathrm{AMPdN}, 10026 / 03$, Inventario General del Archivo. 1820. F. 47, doc. 145. Apéndice documental, $\mathrm{n}^{0}$. 1 .
} 
Así pues, nos encontramos con la curiosa incongruencia de que, el documento ganado del infante en que el concejo logró que no se nombraran sus oficiales de vando a vando no corresponde en su sentido, en el que pretendió el concejo interpretarlo, a tenor de las referencias al mismo en las cuentas municipales, con la normativa que realmente Fernando de Antequera estableció posteriormente, ante presumibles quejas de los bandos. Efectivamente, la tesis defendida por el concejo parece responder menos a la elección de cargos entre personas no alineadas en alguna de las dos facciones que a postular que ésta no había de responder al reparto equitativo entre ellas. Esta actitud, en definitiva, lo que parece camuflar es el intento de predominio de uno de los partidos sobre el otro. De este modo, las declaraciones de haber nombrado a personas sin bando por parte del concejo y de algunos oficiales de no pertenecer a los mismos pese a haber sido apuntados como tales responden más bien al apoyo a la disciplina interna de la parcialidad que trataba de marginar a su rival y a la justificación del incumplimiento de las ordenanzas señoriales en beneficio propio ${ }^{83}$.

A su vez, la recepción por representantes de ambos bandos del corregidor y el rechazo del nuevo concejo hacia éste en agosto de 1402, aunque podría dar pie a considerar que miembros neutrales de la elite local pudieran haberse apoderado del gobierno de la villa frente a las dos facciones constituidas, da cabida otra opción explicativa. Aunque, sin duda, podrían existir individuos y familias de caballeros no integradas en los bandos, la pertenencia a uno de ellos no implicaba una ciega e inquebrantable amistad y solidaridad entre todos sus miembros. Dentro de un linaje urbano no era desconocida la plausible competencia entre algunos de sus miembros, que podía derivar en rencillas y colisiones internas de distinta intensidad y mejor o peor solución. Un motivo para este tipo de contradicciones bien puede ser la concurrencia al poder político municipal, que puede dar lugar a una diferencia de intereses no satisfechos entre sectores del mismo bando. Si no, poco sentido tendrían las recurrentes comparecencias ante la corte señorial, tanto de representantes de los bandos como del propio concejo electo, y el consecuente apoyo del infante al reparto equitativo de los oficios entre los miembros de ambas parcialidades que hemos observado. En esta línea, estas organizaciones que aglutinan a las elites locales responden a una dinámica interna similar a la observada en los linajes nobiliarios bajomedievales, en los que las fuerzas centrípetas que los unifican en torno a su tronco central liderado por el cabeza de linaje conviven con un germen de ruptura, motivado por la multiplicación de líneas familiares, como observó M. C. Gerbet al

\footnotetext{
${ }^{83}$ Ibídem. La cita textual resulta bien reveladora en este sentido: “....aparecen varias respuestas dadas por algunos de los Oficiales, quienes espusieron, que ellos estaban nombrados por haberles hecho relación siniestra de que heran de vando, y acostados a vando, < siendo así que no lo eran $>$, ni permitiese Dios que lo fuesen, y que si dicho Șeñor Ynfante así lo hubiera savido, no les hubiera elegido por que su voluntad hera no fuese ninguno oficial, no siendo de vando a vando".
} 
estudiar la nobleza de la actual Extremadura ${ }^{84}$, que pueden dar lugar a su disgregación en diferentes ramas dotadas de amplia autonomía en materia política $^{85}$. Esta afirmación es, consecuentemente, aplicable al entorno de vasallos y clientes integrados en el linaje por distintos lazos de parentesco ficticio, patronazgo y fidelidad y comunidades de objetivos, en donde los intereses afrontados de individuos o grupos pueden resultar más dispares todavía y, por tanto, las opciones de conciliarlos con el mantenimiento de las lealtades existentes son, si cabe, menores ${ }^{86}$. Así pues, en aquellas construcciones como los linajes, bandos y parcialidades urbanos, los elementos de dispersión adquieren una dimensión más evidente y reveladora frente a los de agregación, siendo mucho menor el peso de los nexos de parentesco real - y no refiriendo éstos normalmente a un único tronco común -, y prioritaria la sintonía y alianza en términos políticos, sociales y económicos entre distintos grupos familiares del sector oligárquico local. Trabajos recientes han llamado la atención, precisamente, sobre el valor de las formas de pacto entre linajes y bandos urbanos en la Castilla bajomedieval, tanto en casos en los que éstos estaban claramente formalizados como en otros en que su carácter es más difuso y coyuntural. Por un lado, como fórmulas de contractualismo entre las facciones. Pero, por otro, como expresión de los intereses particulares de elementos integrados en estas organizaciones, que afectaban a otros individuos y familias no necesariamente pertenecientes a sus mismos grupos de afinidad política, pero no por ello obligaban en bloque a todo el linaje. Esto es, como manifestaciones de la necesidad de conciliar dos premisas para garantizar la

\footnotetext{
${ }^{84}$ Marie Claude Gerbet, La nobleza en la Corona de Castilla. Sus estructuras sociales en Extremadura (1454-1516), Cáceres, 1989, pp. 97-101.

${ }^{85}$ Isabel BECEIRO PITA; Ricardo CÓRDOBA DE LA Llave, Parentesco, poder y mentalidad. La nobleza castellana, siglos XII-XV. Madrid, 1990, p. 309. Más allá de si es posible una equiparación entre las formas de familia de los grupos nobles urbanos y los de la alta nobleza, como considera M. DIAGO HERNANDO (El papelde los linajes, pp. 174-175) o no es posible por la mayor formalidad y reglamentación del linaje nobiliario, como defiende J.M ${ }^{\mathrm{a}}$. MONSALVO ANTÓN (Parentesco y sistema concejil, p. 956), el planteamiento por nosotros formulado, en cualquier caso, no supone una asimilación entre las estructuras denominadas por las fuentes como linajes, propios de los grupos de las elites urbanas castellanas (para una posible clasificación de las distintas realidades denominadas a partir de este término, ibidem, pp. 947-950,) y las formas organizativas familiares de la nobleza bajomedieval definidas como linajes (I. BECEIRO PITA; R. CORDOBA DE LA LLAVE, Parentesco poder, pp. 97-118 para una definición del linaje nobiliario). El carácter polisémico del término linaje en la documentación medieval, sobre todo en relación con el mundo urbano, ha de evitar, en nuestra opinión, una aplicación demasiado laxa del concepto si entendemos que, rigurosamente, era otorgado a aparatos organizativos diferentes y que, en caso contrario, puede dar lugar a una identificaciones equivocas, particularmente delicadas cuando se da el salto del estudio del caso local a la sistematización regional o para un ámbito general como toda la Corona de Castilla.

${ }^{86}$ Las referencias a "parientes, amigos y los otros que con ellos quisieran ser o que a ellos se quisieran allegar" que recogíamos en la nota 61 para caracterizar a los individuos adscritos a las parcialidades dentro de los documentos que estamos manejando para nuestro estudio, precisamente refieren esós vínculos personales de parentesco real y ficticio, patronazgo, amistad y afinidad política, social o economica de mayor o menor intensidad que caracterizan las relaciones en el seno de estas facciones.

Por otro lado, hemos tenido ocasión recientemente de acercarnos al problema de considerar los intereses y la capacidad de influencia de clientes y criados a la hora de analizar la confección de las estrategias de una Casa nobiliaria a partir del ejemplo ofrecido por el reparto de la herencia castellana del propio Fernando de Antequera (V. MUNOZ GómEZ, Transmisión patrimonial y estrategias de linaje. La herencia de Fernando de Antequera (1415-1420), en "Homenaje al profesor Julio Valdeón Baruque". En prensa).
} 
operatividad de estas entidades: por una parte, la búsqueda de acuerdos entre partidos rivales en cuanto al reparto de la influencia política local para la conservación de un determinado equilibrio de poderes en el marco municipal; por otra, el mantenimiento de la solidaridad interna entre miembros en el seno de cada uno de estos organismos con el fin de asegurar la operatividad de los mismos en el juego político local ${ }^{87}$.

\section{CONCLUSIONES}

Así, para recapitular, pese a las exiguas pruebas documentales que hemos podido manejar, el conflicto desarrollado entre 1401 y 1403 por el control del gobierno concejil en la villa terracampina de Paredes de Nava, nos ha permitido aproximarnos al análisis de las formas de competencia por el poder político de las elites urbanas castellanas de la Baja Edad Media. Aunque no se nos antoja como algo inviable que, aunque debieron de existir individuos dentro de la elite local paredeña no integrados en ninguna de las facciones de las que hemos venido hablando, aunque algunos de ellos pudieron tener una intervención relevante dentro del contexto conflictivo vivido en la villa durante esos años, podemos afirmar que éste se hubo de verse protagonizado preferentemente por una mayoría de este sector social dominante dividido en dos bandos que tenían como una de sus principales razones de ser el reparto del gobierno municipal. Acaso no podamos dar respuestas solventes en torno a la composición y organización de estos partidos, ni tampoco sepamos ciertamente cuál pudo ser el punto de acuerdo entre ellos al respecto del acceso al concejo tras el asentamiento del corregidor señorial en la villa. Pero, pese a que seguramente sus estructuras carecían de la institucionalización que alcanzaron otras formas de parcialidad en muchas ciudades castellanas situadas entre el Duero y el Sistema Central, efectivamente, en Paredes de Nava a principios del siglo XV, existían ciertos vandos como expresión de una concurrencia faccionada al poder político concejil, dotados de una organización escasamente formalizada pero basada en lógicas internas complejas, difíciles de rastrear en la documentación con que el medievalista suele contar a su disposición. Y, más aún, a razón de la persistencia de diferentes conflictos en el seno de la villa entre 1396 y 1427 que afectaban a la participación en el poder municipal, contamos con razones para pensar en una cierta durabilidad a lo largo del tiempo de estas formas de alineación de la

\footnotetext{
${ }^{87}$ Nos referimos a los artículos de María ASENJO GonZÁLEZ, Concordia, pactos y acuerdos en la sociedad política urbana de la Castilla bajomedieval, pp. 125-157; José Antonio JARA FUENTE, Vecindad y parentesco. El lenguaje de las relaciones políticas en la Castilla urbana del siglo XV pp. 211-239; Yolanda GUERRERO NAVARRETE, Rey, nobleza y élites urbanas en Burgos (siglo XV), pp.241-279; pero particularmente el de J.M ${ }^{\mathrm{a}}$ MONSALVO ANTóN, En torno a la cultura contractual de las élites urbanas: pactos y compromisos políticos (linajes y bandos en Salamanca, Ciudad Rodrigo y Alba de Tormes), pp. 159-209, aparecidos en el reciente libro editado por Francois FORONDA; Ana Isabel CARRASCO MANCHADO (dirs.) El contrato político en la Corona de Castilla. Cultura y sociedades políticas entre los siglos X al XVI, Madrid, 2008.
} 
elite local, más allá del carácter coyuntural que se les podría atribuir a primera vista.

Por otro lado, los indicios que manejamos sobre la problemática del reparto de los oficios del concejo que los enfrentó entre 1401 y 1403 nos remiten a una dinámica común en muchas ciudades castellanas de la época, de pugna alrededor de la participación y ejercicio del poder municipal al calor de los procesos de aristocratización u oligarquización de las instancias políticas urbanas. Ésta hunde sus raíces en las transformaciones sociales de los siglos XIII y XIV y se extiende a lo largo del siglo XV hasta los albores del siglo XVI, pero pasó, precisamente en la segunda mitad del siglo XIV y los inicios del siglo XV, por una fase de severa efervescencia a partir de la introducción de las regidurías en el organigrama institucional de los concejos ${ }^{88}$. Así, la instauración del regimiento, que suponía el reconocimiento a la decantación elitista de los sistemas concejiles, daría lugar a nuevas situaciones de conflicto de cara a la definición de las agencias políticas locales y a la organización de los grupos dirigentes de un modo estable y coherente respecto a los diferentes intereses encontrados. En consecuencia, éstas exigirían de la puesta en juego de diversos mecanismos de pacificación entre los sectores opuestos para el asentamiento de las estructuras de dominación y de ciertos elementos sociales dirigentes en el centro de las mismas. En muchos casos, precisamente, la acción de la Corona y de los señores fue decisiva para garantizar tanto la pacificación y acuerdo entre los actores enfrentados como la consolidación de la fracción social dominante en los escenarios urbanos ${ }^{89}$.

Finalmente, a partir de el conflicto aquí estudiado podemos preguntarnos acerca del modo en que los poderes señoriales afrontaron este tipo de enfrentamientos por el gobierno municipal en los medios urbanos bajo sus jurisdicciones que, en último término, podían afectar seriamente al ejercicio de sus potestades sobre estas villas. Apenas hemos podido esbozar algunas de las líneas seguidas por el infante Fernando y sus servidores a la hora de atajar una pugna sin duda contraria a sus propios intereses. No obstante, sería más que interesante profundizar en esta línea de análisis, en tanto en cuanto puede ofrecernos una interesante perspectiva del marco de relación existente entre los elementos políticos del sistema concejil y las instancias señoriales en la Castilla del final de la Edad Media.

\footnotetext{
${ }^{88}$ En relación con las transformaciones de los siglos XIII-XIV, H. CASADO ALONSO, Las relaciones poder real-ciudades en Castilla en la primera mitad del siglo XIIV; Y Adeline RUCQUOI,
Pouvoir royal et oligarchies urbaines d'Alfonso X à Fernando IV de Castille, en A. RUCQUOI (coord.), Génesis medieval del Estado Moderno. Castilla y Navarra (1350-1370), Valladolid, 1987, pp. 173-192 y 193-216, respectivamente.

${ }^{89}$ Este tema es brillantemente analizado, aportando una interpretación de conjunto para toda la Corona de Castilla, en el artículo de J.A. JARA FUENTE, Estructuras formales de poder y de en el siglo XV, "Edad Media. Revista de Historia", 8 (2007), pp. 225-241.
} 


\title{
APÉNDICE DOCUMENTAL
}

\begin{abstract}
1
1401, junio, 9. Paredes de Nava.

Descripción extraída del antiguo inventario del archivo municipal de la reunión del concejo de la villa para el nombramiento de nuevos oficiales. Se presentó carta del señor, el infante don Fernando, en que revocaba su anterior mandato sobre el nombramiento de los mismos a causa las quejas recibidas por uno de los bando de la villa, ordenando que se tomaran nuevos oficiales, a partes iguales entre los bandos, no valiendo los previamente elegidos, todo lo cual el concejo acató y cumplió pese a protestarlo como contrario a sus fueros y derechos
\end{abstract}

AMPdN, 10026/03. Inventario General del Archivo. 1820. F. 47 r. y v. Doc. 145

Juntas del concejo de esta villa, hechas en nueve de Junio, de mil cuatrocientos y un años, por ante el Notario Alfonso Fernández, en las que se presentó una carta del Ynfante don Fernando, en que se hace relación que por otra su carta tenía mandado que nombrasen en esta dicha su Villa oficiales de ambos los Vandos, tantos de una parte como de la otra, por ciertas razones que contenía: que si en el repartir de los Oficios los Vandos no se aviniesen, nombrasen tales hombres que no fuesen de alguno de los Vandos, y que si habían nombrado Oficiales, los bolbiesen a nombrar. Y que hera querellado por parte de aquellos del un Bando, que fuera handaban, y por quienes se había requerido con dicha su carta, que no lo habían querido hacer según se les mandaba: Que visto lo que por una y otra parte aclaró de varios Sugetos, que ante él fueron, y de quien recivió Juramento en razón de aclarar quienes heran pertenecientes del Vando contrarios de los que fuera handaban, para haber la mitad de los dichos oficios; e igualmente de los pertenecientes a el otro Vando; e hicieron el nombramiento por mitad, dos Alcaldes del uno y dos del otro, lo mismo con respecto a los demás Oficios, entre los cuales hay el de tener las Llaves del Sello del Concejo: dio por ninguno el anterior nombramiento, y que sirbiesen los electos ahora hasta Pascua de Resurrección del siguiente año, que hera la costumbre, reciviendo de ellos juramento.

En este Concejo se ovedeció, y cumpliéndola recivieron por tales Oficiales a los nuevamente nombrados, de los cuales recivieron Juramento el comisionado según se mandava; pero que hera en gran daño e perjuicio de esta Villa como lo manifiestan en diligencia separada, lo primero por que dicho Señor Ynfante savía que esta Villa y su Concejo tenían Privilegios de los Reyes donde él venía, confirmados, y aún del Rey presente, de tanto tiempo, que memoria de Hombres no había en contrario, de poner Alcaldes, Regidores, Procuradores y/v. demás oficios de una vez cada año, sin haberles sido contradicho por los Señores que fueran de la dicha Villa, poniendo Jueces, y Oficiales, salbo si Juez, o Jueces les fuesen pedidos por parte del Concejo: lo segundo, por que cuando a dicho Señor Ynfante le fue hecho homenage por el citado Concejo, de la enunciada Villa, prometió guardar su Privilegios, franquezas y 
livertades en manos del conde don Enrrique, su tío; Y lo tercero, por que habiendo nombrado ellos los Oficiales en Hombres buenos, y llanos, sin vando, ni bullicio alguno, el Señor Ynfante los quitara; todo lo cual harían ver, para que les fuesen guardados sus Privilegios.

Consta haberse recivido juramento a los nombrados, y aparecen varias respuestas dadas por algunos de los Oficiales, quienes espusieron, que ellos estaban nombrados por haberles hecho relación siniestra de que heran de vando, y acostados a vando, < siendo así que no lo eran>, ni permitiese Dios que lo fuesen, y que si dicho Señor Ynfante así lo hubiera savido, no les hubiera elegido por que su voluntad hera no fuese ninguno oficial, no siendo de vando a vando.

Se halla rubricado al principio, y al fin por el mismo que lo hizo en el Ynstrumento puesto en el número 57.

s.l.s.f.

Descripción extraída del antiguo inventario del archivo municipal de la representación hecha por el concejo de Paredes de Nava al señor de la villa, pidiéndole licencia para revocar la ordenanza que habían hecho para la elección de los oficios entre personas no adheridas a bando y volver a realizar estas elecciones como tenían costumbre anteriormente.

AMPdN, 10026/03. Inventario General del Archivo. 1820. F. 51 r. y v.. Doc. 162

Representación hecha por el Concejo, Alcaldes y Regidores de esta villa, a el señor de ella, en que consta, que por una de las ordenanza que se habían hecho, y su Señoría había aprovado, lo hera una en que se ordenaba, que el día de año nuevo, o su Víspera, se juntasen los Alcaldes, Regidores y Procuradores en la Casa de Concejo, y vajo de Juramento que prestasen, hiciesen elección en cada un año, de cuatro Personas de cada Varrio, que fueren idóneas, y non aderidas a partido alguno, las cuales Juntas, así nombradas, hechasen suertes para ver a quién tocaba ser Regidores, y oficiales, y en quienes recayesen, que hubiese dicho Oficio; cuya ordenanza la habían hecho para que no se hiciese la elección en Persona de Vando; y que si antes de hacer la ordenanza esperimentaban /v.algún daño, o división, al presente esperimentaban aun más, sin embargo de que prestaban Juramento, pues podía llegar el caso de no hallar Personas que no fuesen de partido, y esto hera en perjuicio de sus Conciencias; Por cuyas causas le pidieron licencia, para hacer dicha elección en la forma que se egecutaba antes de arreglar la tal ordenanza.

No hay respuesta, ni firma alguna.

Fecha de recepción del artículo: diciembre 2008.

Fecha de aceptación y versión final: marzo 2009. 